\title{
Global Transcriptional Analysis of Yeast Cell Death Induced by Mutation of Sister Chromatid Cohesin
}

\author{
Qun Ren, ${ }^{1}$ Hui Yang, ${ }^{1}$ Bifeng Gao, ${ }^{2}$ and Zhaojie Zhang ${ }^{1}$ \\ ${ }^{1}$ Department of Zoology and Physiology, University of Wyoming, Laramie, WY 82071, USA \\ ${ }^{2}$ Microarray Core, University of Colorado Health Science Center, Denver, CO 80262, USA \\ Correspondence should be addressed to Zhaojie Zhang, zzhang@uwyo.edu
}

Received 23 December 2007; Revised 31 March 2008; Accepted 22 April 2008

Recommended by Brian Wigdahl

Cohesin is a protein complex that regulates sister chromatid cohesin during cell division. Malfunction in chromatid cohesin results in chromosome missegregation and aneuploidy. Here, we report that mutations of MCD1 and PDS5, two major components of cohesin in budding yeast, cause apoptotic cell death, which is characterized by externalization of phosphatidylserine at cytoplasmic membrane, chromatin condensation and fragmentation, and ROS production. Microarray analysis suggests that the cell death caused by mutation of MCD1 or PDS5 is due to the internal stress response, contrasting to the environmental or external stress response induced by external stimuli, such as hydrogen peroxide. A common feature shared by the internal stress response and external stress response is the response to stimulus, including response to DNA damage, mitochondria functions, and oxidative stress, which play an important role in yeast apoptotic cell death.

Copyright (C) 2008 Qun Ren et al. This is an open access article distributed under the Creative Commons Attribution License, which permits unrestricted use, distribution, and reproduction in any medium, provided the original work is properly cited.

\section{Introduction}

It has been increasingly evident that yeast as well as other unicellular organisms can undergo apoptotic cell death (for recent review, see [1]). The apoptotic cell death shares many morphological and biochemical features with mammalian apoptosis, including DNA fragmentation and chromatin condensation, exposure of phosphatidylserine on the outer membrane surface, leakage of Cytochrome $\mathrm{C}$ from mitochondria [2]. Apoptosis in yeast can be induced by external stresses, such as hydrogen peroxide [3], acetic acid [4], as well as mutations of certain essential genes, such as CDC48 [5], ORC2 [6], and PDS5 [7]. The yeast apoptotic cell death is promoted by proapoptotic genes, including the metacaspase YCA1/MCA1 $[8,9]$ and apoptosis-inducing factor AIF1 [10].

Cohesin is a protein complex that regulates sister chromatid cohesion and is required for ordered chromosome segregation [11]. Cohesin physically links the sister chromatids during replication. This attachment makes it possible for the kinetochore of each sister chromatid to attach to microtubules from different poles. During anaphase, cohesin is released from chromosomes, and proper segregation occurs [12]. Cohesin contains at least four protein subunits: Smc1, Smc3, Mcd1/Scc1, and Scc3 $[13,14]$. In addition to the four subunits, several additional proteins are required to establish or maintain the chromatid cohesion but are not part of the cohesin complex,such as Pds5 [14-17], Scc2, and Scc4 [18]. Scc2 and Scc4, for example, are required for loading the cohesin complex onto chromosomes, but do not colocalize with the complex [18]. Pds5 is essential for both mitosis $[15,16,19]$ and meiosis [20]. Pds5 localizes to chromosomes in a cell cycle-dependent manner and is required for sister chromatid cohesion, chromosome condensation, DNA repair, and proper chromosome segregation.

In addition to its function in chromatid cohesion, studies show that cohesin has a role in apoptosis [21, 22]. Human RAD21/MCD1 is reported as a nuclear caspase target. Induction of apoptosis by diverse stimuli causes the cleavage of hRad21. The cleaved C-terminal product of hRAD21 is translocated from the nucleus to cytoplasm and acts as a nuclear signal for apoptosis. RAD21/MCD1 is also overexpressed in prostate [23] and breast cancer cells [24]. Suppression of RAD21/MCD1 reduces the ability for cell proliferation and increases the level of apoptosis [24]. In yeast (S. cerevisiae), our recent study showed that mutation of PDS5 causes cell death in early meiosis [7].

Here we report that mutation of MCD1 $(\operatorname{mcd} 1-1)$ and PDS5 (pds5-1) showed an apoptotic phenotype, including 


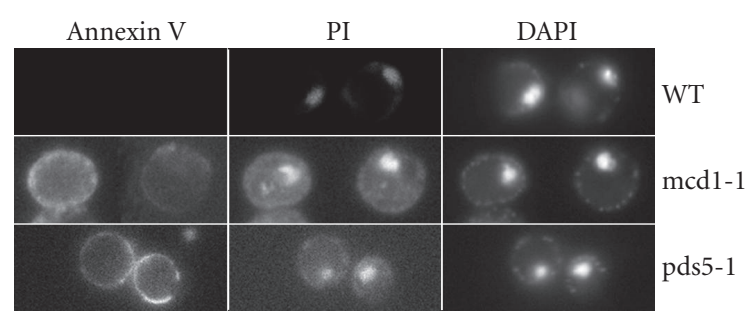

(a)

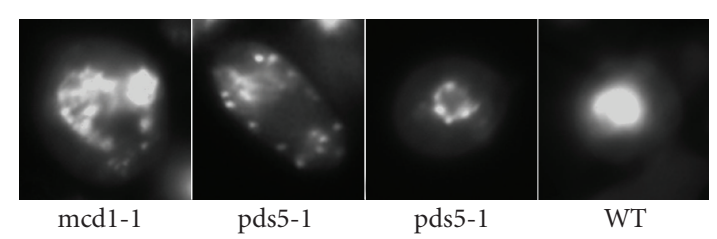

(b)

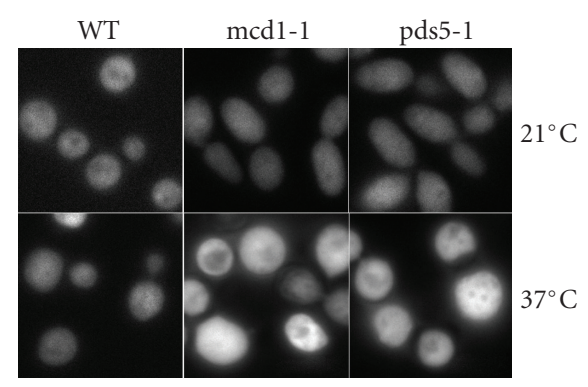

(c)

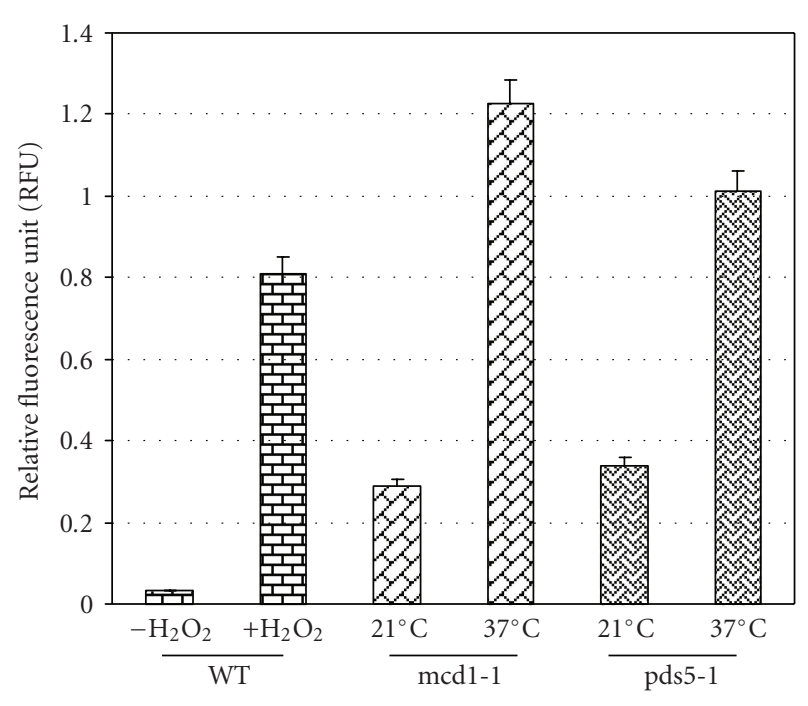

(d)

Figure 1: Apoptotic cell death in mod1-1 and pds5-1 mutants. WT, mcd1-1, and pds5-1 mutants were shifted from permissive temperature $\left(21^{\circ} \mathrm{C}\right)$ to nonpermissive temperature $\left(37^{\circ} \mathrm{C}\right)$ for 12 hours, then stained with (a) Annexin V, PI, and DAPI; (b) DAPI for nucleus and (c) Dihydrorhodamine 123 for ROS. (d) Quantitative measurement of ROS production of $\mathrm{H} 2 \mathrm{O} 2$-treated cells, mcd1-1 and pds5-1 mutants at permissive, and nonpermissive temperature. exposure of phosphatidylserine to the outer membrane, accumulation of DNA breaks, condensation and fragmentation of chromatin, and production of ROS. Microarray analysis of the global transcript of mcd1-1 and pds51 mutants, in comparison with $\mathrm{H}_{2} \mathrm{O}_{2}$ induced apoptosis, showed that the majority of the differentially expressed genes were upregulated. These genes were involved in a variety of functions, including response to stimulus, cell cycle regulation, mitochondrial functions, and cell wall organization. Our data suggest that the cell death caused by mutation of MCD1 or PDS5 is due to response to physiological or internal stress, compared to the $\mathrm{H}_{2} \mathrm{O}_{2}$ treated cells, which is considered response to environmental or external stress.

\section{Results}

\subsection{Mutation of MCD1 and PDS5 Showed Major Markers of Apoptosis}

Our previous report [7] showed that mutation of PDS5 caused apoptotic cell death in yeast during early meiosis. Here, we demonstrated that mutation of PDS5 and MCD1, two cohesin related genes, caused apoptotic cell death during mitosis. Figure 1 shows some of the "hallmarks" of apoptosis - the translocation of phosphatidylserine from the inner leaflet to the outer leaflet of the plasma membrane (Figure 1(a)), and nuclear fragmentation (Figure 1(b)). ROS accumulation was also observed in mcd1-1 and pds5-1 mutants, when grown at nonpermissive temperature (Figures $1(\mathrm{c})$ and $1(\mathrm{~d}))$. Note that the ROS level was higher in mcd1-1 and pds5-1 mutants even at $21^{\circ} \mathrm{C}$ (Figure $1(\mathrm{~d})$ ), compared to the wild type.Chromatin condensation was also observed by transmission electron microscopy (Figure 2).

\subsection{General Characteristics of Gene Expression}

In attempt to understand the mechanism of the cohesininduced apoptosis in yeast, a global analysis of gene expression was performed in mcd1-1 and pds5-1 mutants undergoing apoptotic cell death. $\mathrm{H}_{2} \mathrm{O}_{2}$-treated cells were used as a positive control.The number of up- and downregulated genes were shown in Figure 3 (the original data is available at http://www.uwyo.edu/microscopy/cohesin.xls).The microarray data were further validated by reverse transcriptasepolymerase chain reaction (RT-PCR) (Figure 4).5 different genes from each group were chosen for RT-PCR analysis. These genes represent genes that are up- and downregulated, and genes related to cohesin complex, which is of interest for further analysis. At both time points (see materials and methods for determination of the time points), more genes were upregulated than downregulated, suggesting a genetic program was being activated, rather than the general gene expression shutdown that might be expected in a rapid cell death. At time point 1, pds5-1 had more genes differentially regulated than the other two, while mcd1-1 had the least. At time point 2 , however, the number of differentially regulated genes in mcd1-1 surpassed that of pds5-1 or $\mathrm{H}_{2} \mathrm{O}_{2}$-treated 


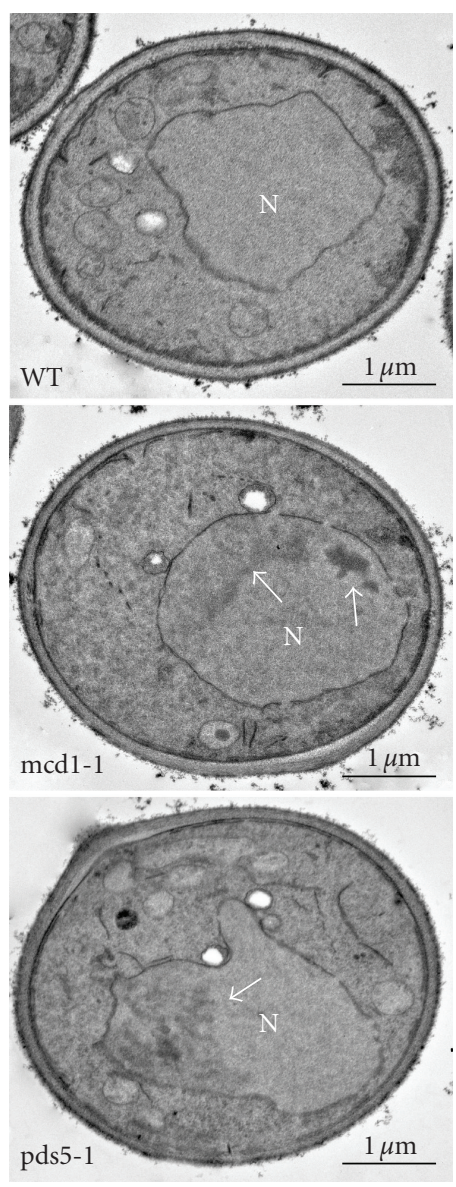

Figure 2: TEM images of mcd1-1 and pds5-1 mutants, growing at nonpermissive temperature for 2 hours, showing chromatin condensation (arrow in mcd1-1 and pds5-1) $N=$ Nucleus.

cells, especially the number of upregulated genes (Figures 3 , 5). Furthermore, while the number of differentially regulated genes in pds5-1 and $\mathrm{H}_{2} \mathrm{O}_{2}$-treated cells decreased from time point 1 to time point 2 , the number of genes in $\operatorname{mcd} 1-1$ increased from time point 1 to time point 2 . These results suggest that cells may have a slower but more profound response at later time point, to the defect of Mcd1, than to the defect of Pds5, or $\mathrm{H}_{2} \mathrm{O}_{2}$-treated cells.

Only a small number of differentially expressed genes overlap among the three groups in both time points (Figure 5). The total number of overlapped genes were 174 in time point 1 (167 upregulated, and 7 downregulated) and 349 in time point 2 (323 upregulated and 26 downregulated). This suggests that these three groups may undergo apoptotic cell death through different pathways. To better understand the pathways, the gene expression profiles were analyzed using Netaffx analysis software from Affymetrix (http://www.affymetrix.com/). Using Affymetrix's gene ontology (GO) mining tool, it was found that in $\mathrm{H}_{2} \mathrm{O}_{2}$-treated cells, the most prominent group of genes (the group with the lowest $\rho$-value) that were differentially expressed was "response to stimulus" (Table 2). In mcd1-1 and pds5-1 mutants, however, the most prominent

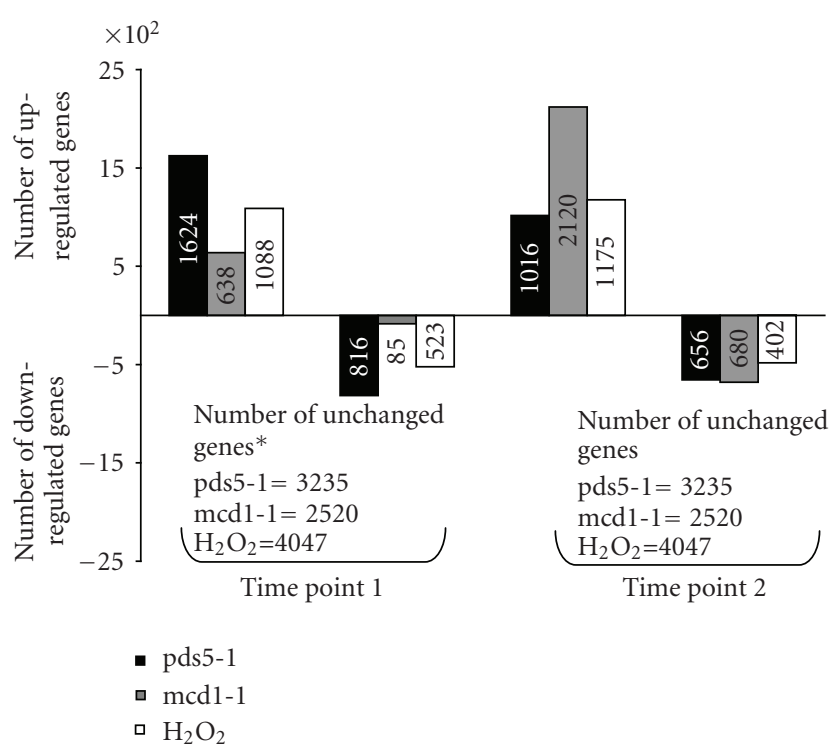

Figure 3: Number of up- and downregulated genes at time point 1 and point 2 in $\mathrm{H}_{2} \mathrm{O}_{2}$-treated cells, mcd1-1, and pds5-1 cells. ${ }^{*}$ The number of unchanged genes includes genes with marginal increase and marginal decrease (see Materials and Methods for detail).

group is related either to physiological process (mcd1-1), or regulation of biological process (pds5-1). This may reflect the fact that the $\mathrm{H}_{2} \mathrm{O}_{2}$-treated cells mainly responded to the external stress, termed "environmental stress response" (ESR) [25], while in mcd1-1 and pds5-1 mutants, the gene expression responded mainly to biological or physiological changes due to the malfunction of MCD1 or PDS5.

\subsection{Genes Involved in Response to Stimulus}

When the 174 overlapped genes from the three groups in time point 1 were analyzed using the GO mining tool, it was found that the most prominent group of differentially expressed genes was related to "response to stimulus" (Table 2), suggesting that, like the $\mathrm{H}_{2} \mathrm{O}_{2}$-treated cells, the mcd1-1 and pds5-1 mutants, when grown at nonpermissive temperature, were also under stress. An evidence of the stress was the production of ROS (Figure 1). The changes of gene expression in mcd1-1 and pds5-1 mutants were referred to "internal stress response" (ISR), contrasting to the environmental, or external stress response (ESR). At time point 2, the most prominent change of gene expression in all types of cells, including $\mathrm{H}_{2} \mathrm{O}_{2}$-treated cells, was related to either physiological process (mcd1-1), or regulation of biological process (pds5-1 and $\mathrm{H}_{2} \mathrm{O}_{2}$-treated), suggesting that the ESR could eventually become ISR, if the stress continues.

Further analysis of the overlapped genes of the three groups revealed that at time point 1,29 out of 174 of the overlapped genes were a response to stimulus, including response to DNA repair, oxidative stress, heat and nutrition (Table 3). Only 3 out of 29 were downregulated and 26 were upregulated. In time point 2 , response to stimulus was one 


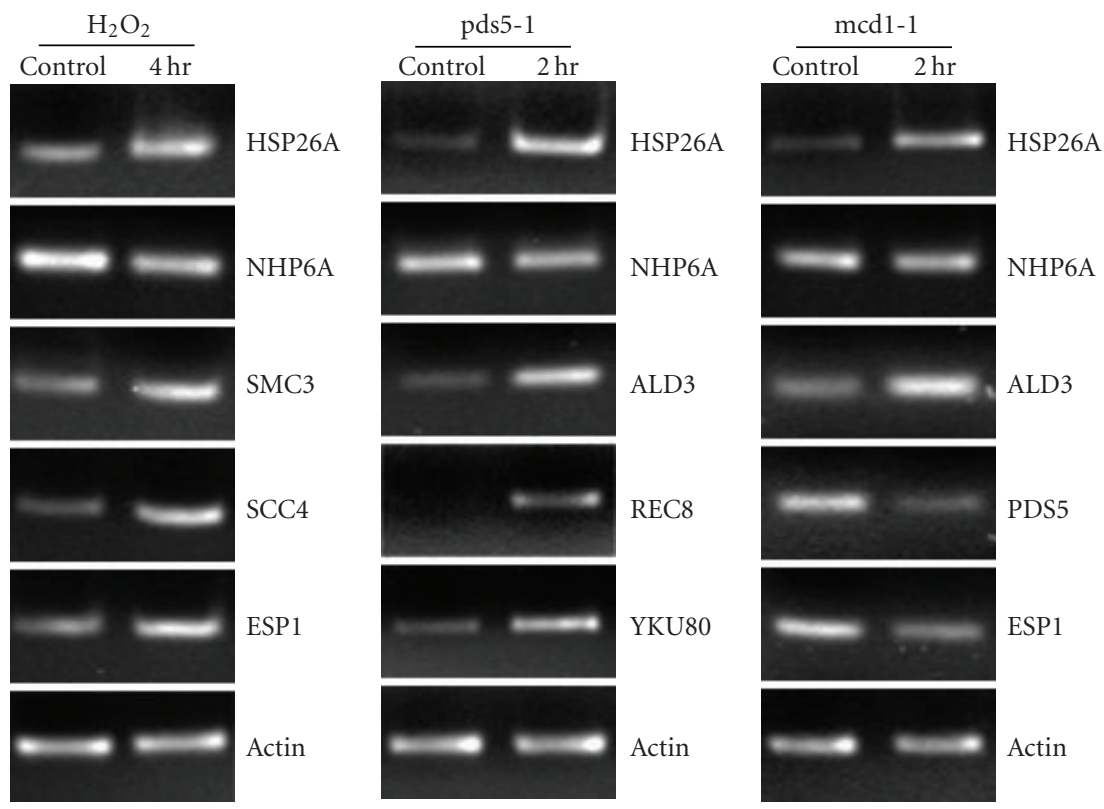

FigURE 4: RT-PCR of 5 different genes from each group of time point 1.

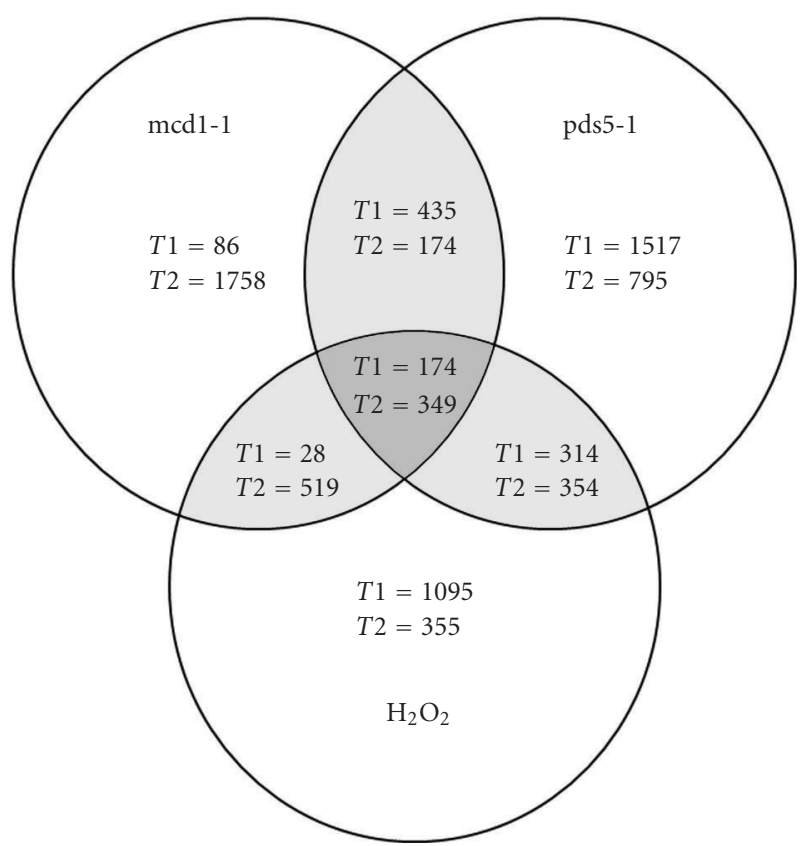

FIGURE 5: Schematic representation of differentially expressed genes in the three groups. T1: time point 1; T2: time point 2.

of the top three prominent groups that are differentially regulated $(1 \mathrm{st}=$ regulation of biological process (Table 2$)$, 2nd $=$ development, $3 \mathrm{rd}=$ response to stimulus). Among the 58 differentially regulated genes response to stimulus, $31(53 \%)$ were related to DNA damage (Table 4$)$, suggesting that more DNA damages were caused by the extended time of internal or external stress. It has been reported that both Pds5 and Mcd1 are involved in DNA repair $[26,27]$. The elevated number of differentially expressed genes response to DNA damage could be related in part, to the malfunction of mcd1-1 or pds5-1 in DNA damage repair.

Previous reports indicate that both Pds5 [27, 28] and Mcd1 [26] have a role in DNA repair. To explore if the defect in DNA repair is involved in mcd1-1- or pds5-1-induced apoptosis, wild type, pds5-1- and mcd1-1 cells were exposed to UV radiation $\left(150 \mathrm{~J} / \mathrm{m}^{2}\right)$ using a UV cross-linker (Stratagene, Inc.), and then incubated for 20 hours at $37^{\circ} \mathrm{C}$ before being assayed with DAPI. DAPI staining showed that in pds51 , broken nuclei increased at least $18 \%$, while in mcd1-1, 
TABLE 1: Fold changes of each gene expression, corresponding to the RT-PCR in Figure 4.

\begin{tabular}{|c|c|c|c|c|c|}
\hline \multicolumn{2}{|c|}{$\mathrm{H}_{2} \mathrm{O}_{2}$} & \multicolumn{2}{|c|}{ pds5-1 } & \multicolumn{2}{|c|}{$\operatorname{mcd} 1-1$} \\
\hline GENE & Fold change & GENE & Fold change & GENE & Fold change \\
\hline HSP26A & +10.6 & HSP26A & +30 & HSP26A & +9.8 \\
\hline NHP6A & -4 & NHP6A & -2.3 & NHP6A & -2 \\
\hline SMC3 & +8 & ALD3 & +52 & ALD3 & +12 \\
\hline SCC4 & +9.8 & REC8 & +19.7 & PDS5 & -1.7 \\
\hline ESP1 & +6.1 & YKU80 & +7.5 & ESP1 & -1.3 \\
\hline Actin & Control & Actin & Control & Actin & Control \\
\hline
\end{tabular}

TABLE 2: The most prominent gene group (the group with the lowest $\rho$-value) that is differentially expressed in response to the $\mathrm{H}_{2} \mathrm{O}_{2}$ treatment, or MCD1 and PDS5 mutations.

\begin{tabular}{lcc}
\hline & \multicolumn{1}{c}{ Time point 1 } & Time point 2 \\
\hline mcd1-1 & Physiological process (GO ID = 7582) & Physiological process (GO ID = 50789) \\
pds5-1 & Regulation of biological process (GO ID = 50789) & Regulation of biological process (GO ID = 50789) \\
$\mathrm{H}_{2} \mathrm{O}_{2}$ & Response to stimulus (GO ID = 50896) & Regulation of biological process (GO ID = 50789) \\
All three & Response to stimulus (GO ID = 50896) & Regulation of biological process (GO ID = 50789) \\
\hline
\end{tabular}

broken nuclei increased about 15\%, compared to cells without UV radiation. At the same condition, UV radiation had almost no effect on wild type (Figure 6(a)). ROS levels were much higher in mcd1-1 and pds5-1 mutants after UV radiation (Figure 6(b)). These results suggest that (1) Mcd1 and Pds5 participate in DNA break repair, and (2) defect of mcd1-1 or pds5-1 in DNA break repair plays a role in apoptosis.

\subsection{Genes Involved Mitochondria Functions}

Mitochondria play an important role in yeast apoptosis $[29,30]$. In our current study, microarray analysis revealed that many differentially expressed genes were localized in mitochondria. In time point 1 , among the 174 differentially expressed genes in all three groups, 38 were found localized in mitochondria (Table 5). 26 of the 38 genes were localized only in mitochondria. Interestingly, 12 of the 38 have unknown functions. The genes that have known functions were involved in response to stimulus, constituents of mitochondrial membrane, regulation of ATP syntheses, and other enzymes. Of particular interest is the upregulation of CYC7, which encodes the isoform 2 of Cytochrome C. Cytochrome $\mathrm{C}$ has been reported to be released from mitochondria to cytoplasm after induction of apoptosis [31]. The increase of expression level of CYC7 may also contribute to the release and the abundance of Cytochrome $\mathrm{C}$ in cytoplasm after induction of apoptosis. The upregulation of CYC7 only appeared in time point 1 , not time point 2, suggesting that the release of Cytochrome $\mathrm{C}$ is an early event during apoptosis. At time point 2, 40 (12 localized only mitochondria; 8 with unknown functions) of the commonly up- or downregulated genes were found localized in mitochondria. Although the number of genes was similar to that of time point 1 , the majority of genes were different and only 7 appeared in both time points (bold letters in Tables 5 and 6). Of the 7 genes, 3 (ELG1, NTG1, and NTH2) were response to stimulus/DNA repair; 3 (GCV1, GLT1, and AEP1) were related to amino acid/protein metabolism; and one (YDR332W) with unknown functions. In general, the mitochondrial genes were mainly involved in response to stimulus/DNA damage repair, metabolism of DNA, proteins, and amino acids. BIR1, the gene encodes an antiapoptotic protein, was found overexpressed in all three cases (Table 6). When checked at time point 1, BIR1 was also overexpressed in all three cases, but the fold change in mcd1-1 was less than 2, and therefore was filtered out. Because BIR1 is also involved in coordinating cell cycle events for proper chromosome segregation, it is unclear that the overexpression of BIR1 is due to its role of cell cycle control, or apoptosis.

\subsection{Genes Involved in Cell Cycle Regulation}

Deregulation of cell cycle has been reported in yeast cells undergoing apoptotic cell death [32, 33]. The apoptotic aging cells, for example, were described as to attempt the second budding cycle without the completion of the first one. Irregular expression of cell cycle related genes was also reported in old cells and orc2-1 cells that underwent apoptosis [33]. In our current study, we found that 62 genes that were differentially expressed in all three groups at time point 2 were related to cell cycle regulation (Table 7), while only 12 in time point 1 were related to cell cycle, suggesting that this deregulation occurs at the late stage of apoptosis. Cell cycle interruption was also observed at time point 1 . In mcd-1-1 mutant, for example, SEM images showed the daughter cell was unable to bud off the mother cell even when the size of the daughter cell was similar to the size of the mother cell (Figure 7(a)). The 62 all upregulated genes 
TABLE 3: List of differentially regulated genes response to stimulus in time point 1.

\begin{tabular}{|c|c|c|c|c|c|}
\hline \multirow{2}{*}{ Response to } & \multirow{2}{*}{ Gene } & \multicolumn{3}{|c|}{ Fold change } & \multirow{2}{*}{ Description } \\
\hline & & $+\mathrm{H}_{2} \mathrm{O}_{2}$ & $\operatorname{mcd} 1-1$ & pds5-1 & \\
\hline \multirow{6}{*}{ DNA damage } & RMI1 & 10.56 & 2.83 & 9.85 & Involved in response to DNA damage \\
\hline & RFX1 & 8.57 & 2.14 & 6.50 & Involved in DNA damage checkpoint pathway \\
\hline & EPL1 & 7.46 & 2.14 & 6.96 & Component of $\mathrm{NuA} 4$, a histone $\mathrm{H} 4 / \mathrm{H} 2 \mathrm{~A}$ acetyltransferase complex \\
\hline & NTG1 & 6.96 & 2.30 & 7.46 & DNA N-glycosylase and apurinic/apyrimidinic (AP) lyase \\
\hline & YKU80 & 6.96 & 2.14 & 7.46 & Subunit of the telomeric Ku complex (Yku70p-Yku80p) \\
\hline & NHP6A & -4.00 & -2.00 & -2.30 & High-mobility group nonhistone chromatin protein \\
\hline \multirow{4}{*}{ oxidative stress } & SRX1 & 21.11 & 3.73 & 9.19 & Sulfiredoxin \\
\hline & HSP12 & 11.31 & 2.46 & 8.57 & $\begin{array}{l}\text { Plasma membrane localized protein that protects membranes from } \\
\text { desiccation }\end{array}$ \\
\hline & CTT1 & 10.56 & 4.92 & 17.15 & Cytosolic catalase $\mathrm{T}$ \\
\hline & GRE3 & 8.57 & 2.46 & 13.00 & Aldose reductase \\
\hline \multirow{6}{*}{ Heat } & HSP26 & 10.56 & 9.85 & 29.86 & Small heat shock protein with chaperone activity \\
\hline & GRE3 & 8.57 & 2.46 & 13.00 & Aldose reductase \\
\hline & SSA3 & 8.00 & 2.46 & 12.13 & ATPase involved in protein folding and the response to stress \\
\hline & SSA4 & 8.00 & 2.14 & 11.31 & Heat shock protein that is highly induced upon stress \\
\hline & SSE2 & 6.50 & 2.00 & 8.00 & Member of the heat shock protein 70 (HSP70) family \\
\hline & NTH2 & 13.93 & 2.00 & 10.56 & Putative neutral trehalase \\
\hline \multirow{12}{*}{ nutrition \& others } & ALD3 & 19.70 & 12.13 & 51.98 & Cytoplasmic aldehyde dehydrogenase \\
\hline & PTR3 & 9.19 & 3.03 & 12.13 & Component of the SPS plasma membrane amino acid sensor system \\
\hline & DDR2 & 8.57 & 6.50 & 17.15 & Multistress response protein \\
\hline & FIG2 & 8.57 & 3.25 & 8.57 & Cell-wall adhesin \\
\hline & ADR1 & 8.57 & 3.03 & 9.85 & Carbon source-responsive zinc-finger transcription factor \\
\hline & YGP1 & 8.00 & 3.03 & 10.56 & Cell-wall-related secretory glycoprotein \\
\hline & HAL1 & 7.46 & 2.83 & 6.50 & Cytoplasmic protein involved in halotolerance \\
\hline & TSL1 & 6.96 & 4.29 & 13.93 & $\begin{array}{l}\text { Large subunit of trehalose 6-phosphate synthase/phosphatase } \\
\text { complex }\end{array}$ \\
\hline & MET4 & 6.50 & 2.46 & 9.19 & Lecine-zipper transcriptional activator \\
\hline & MPT5 & 6.50 & 2.00 & 9.19 & Member of the Puf family of RNA-binding proteins \\
\hline & PHO5 & -2.46 & -2.14 & -2.00 & Repressible acid phosphatase \\
\hline & TIR1 & -2.83 & -2.64 & -2.00 & $\begin{array}{l}\text { Cell wall mannoprotein of the Srp1p/Tip } 1 p \text { family of serine-alanine- } \\
\text { rich proteins }\end{array}$ \\
\hline \multirow{2}{*}{ Unknown } & YIL169C & 10.56 & 3.73 & 27.86 & Putative protein of unknown function \\
\hline & YOR019W & 9.19 & 2.46 & 10.56 & Hypothetical protein \\
\hline
\end{tabular}

(Table 7) were involved in both mitotic and meiotic cell cycles. 6 genes were involved in mitotic spindle checkpoint (MAD2, MAD3, DMA2, SGO1, IBD2, and MPS1); 3 in DNA damage checkpoint (PIN4, MEC3, LCD1) and two with unknown functions. Of the two genes with unknown functions, YOR019W interacts with ribosomes, and SPR6 was involved in sporulation. Stress, especially external (environmental, nutritional) stress, is the major cause of meiosis or sporulation [34]. The fact that 23 out of the 62 genes (Table 7) are involved in meiotic cell cycle suggests that yeast cells under the external $\left(\mathrm{H}_{2} \mathrm{O}_{2}\right)$, or internal (mc1-1 and pds5-1) stress may attempt to initiate meiotic division. REC8, for example, is a meiotic specific gene that is only expressed during early meiosis. Its expression, however, was detected under all three conditions (Table 7). On the mitotic side, many of the differentially expressed genes are involved in checkpoints of G1/S or G2/M transitions, such as SWI4, a DNA binding component of the SBF complex (Swi4pSwi6p) that regulates late G1-specific transcription of targets, including cyclins, and genes required for DNA synthesis and repair. Another example is SFI1, a Centrin (Cdc31p)binding protein, required for progression through $\mathrm{G} 2 / \mathrm{M}$ transition.

\subsection{Genes Involved in Cell Wall Organization}

Scanning electron microscopy was used to investigate the cell morphology under the external and internal stresses. Consistent with the microarray data, the cell surface structure of the pds5-1- and the $\mathrm{H}_{2} \mathrm{O}_{2}$-treated cells was similar, in which cell 
TABLE 4: List of differentially expressed genes in time point 2 response to DNA damage (bold = genes differently expressed in both time points).

\begin{tabular}{|c|c|c|c|c|}
\hline Gene & $\mathrm{H}_{2} \mathrm{O}_{2}$ & $\begin{array}{c}\text { Fold chan } \\
\text { mcd } 1-1\end{array}$ & pds5-1 & Description \\
\hline PSO2 & 14.93 & 6.96 & 9.19 & Required for a postincision step in repair of DNA breaks \\
\hline CST9 & 13.93 & 4.00 & 14.93 & SUMO E3 ligase \\
\hline EAF7 & 13.00 & 2.46 & 9.85 & Subunit of the NuA4 histone acetyltransferase complex \\
\hline MIG3 & 12.13 & 4.29 & 14.93 & Probable transcriptional repressor \\
\hline EPL1 & 12.13 & 3.73 & 8.57 & Component of NuA4 \\
\hline NHP6A & 12.13 & 3.73 & 8.57 & High-mobility group non-histone chromatin protein \\
\hline SCC4 & 12.13 & 2.30 & 9.19 & Subunit of cohesin loading factor (Scc2p-Scc4p) \\
\hline SLX1 & 11.31 & 2.83 & 10.56 & Subunit of 5'-flap endonuclease complex \\
\hline VID21 & 10.56 & 4.59 & 13.00 & Component of the NuA4 histone acetyltransferase complex \\
\hline YKU80 & 10.56 & 3.25 & 9.85 & Subunit of the telomeric Ku complex (Yku70p-Yku80p) \\
\hline RAD59 & 9.19 & 6.50 & 9.19 & Involved in repair of DNA double-strand breaks \\
\hline HPR5 & 9.19 & 2.83 & 9.19 & DNA helicase and DNA-dependent ATPase \\
\hline SIR4 & 9.19 & 2.83 & 7.46 & Silent information regulator that, \\
\hline EAF6 & 9.19 & 2.46 & 7.46 & Esalp-associated factor, subunit of the NuA4 acetyltransferase complex \\
\hline TFB3 & 9.19 & 2.14 & 9.19 & Subunit of TFIIH and nucleotide excision repair factor 3 complexes \\
\hline NTG1 & 8.57 & 3.48 & 7.46 & DNA N-glycosylase and apurinic/apyrimidinic (AP) lyase \\
\hline MGT1 & 8.57 & 2.64 & 9.19 & DNA repair methyltransferase \\
\hline SNF5 & 8.57 & 2.64 & 9.19 & Subunit of the SWI/SNF chromatin remodeling complex \\
\hline HMI1 & 8.57 & 2.46 & 6.96 & Mitochondrial inner-membrane localized ATP-dependent DNA helicase \\
\hline RTT107 & 8.57 & 2.00 & 7.46 & Interacts with Mms22p and is implicated in Mms22-dependent DNA repair \\
\hline EXO1 & 8.00 & 2.64 & 8.00 & 5'-3' exonuclease and flap-endonuclease \\
\hline ELC1 & 8.00 & 2.14 & 11.31 & Elongin $\mathrm{C}$ \\
\hline HEX3 & 8.00 & 2.14 & 6.96 & Protein containing a RING finger domain that interacts with Slx8p \\
\hline DOA1 & 8.00 & 2.00 & 8.57 & WD repeat protein \\
\hline MMS4 & 8.00 & 2.00 & 8.00 & Subunit of the structure-specific Mms4p-Mus81p endonuclease \\
\hline RAD16 & 7.46 & 5.28 & 8.00 & Recognizes and binds damaged DNA in an ATP-dependent manner \\
\hline MEC3 & 7.46 & 2.83 & 6.96 & DNA damage and meiotic pachytene checkpoint protein \\
\hline PIN4 & 7.46 & 2.46 & 9.19 & Involved in $\mathrm{G} 2 / \mathrm{M}$ phase progression and response to DNA damage \\
\hline CAC2 & 7.46 & 2.00 & 8.57 & Component of the chromatin assembly complex \\
\hline LCD1 & 6.96 & 3.48 & 7.46 & Essential protein required for the DNA integrity checkpoint pathways \\
\hline PAN2 & 6.96 & 2.30 & 12.13 & Subunit of the Pan2p-Pan3p poly(A)-ribonuclease complex \\
\hline
\end{tabular}

wall sunk, forming a hole on the cell surface (Figure $7(a)$ ). The mcd1-1 cells appeared to be more damaged than pds51- or $\mathrm{H}_{2} \mathrm{O}_{2}$-treated cells. More cells collapsed, and cell surface was not as smooth as the other two, suggesting a potential cell composition change. The mcd1-1 cells were generally larger than the wild type or the other two. Further examination of the gene expression related to cell wall revealed that only 7 genes in time point 1 and 5 genes in time point 2 were differentially expressed in all three cases (Table 8), suggesting that the cytoskeleton, rather than the cell wall composition or organization, may contribute more to the morphological changes observed by SEM. To test the possibility of the involvement of cytoskeleton in cell-morphology change, rhodamine-conjugated phalloidin was used to stain actin. As shown in Figure 7(b), for the wild type and mutants grown at permissive temperature, actin appeared to be in both polymerized (filaments) and nonpolymerized (monomers) forms. The filamentous actin was usually oriented parallel to the longitudinal axis of the cell, as well as along the cell wall. In $\mathrm{H}_{2} \mathrm{O}_{2}$-treated cells, and mutants grown at nonpermissive temperature, actin was present mostly as monomers, indicating the damage of the cytoskeleton.

\subsection{Apoptotic Cell Death at Nonpermissive Temperature}

Temperature shift in several temperature-sensitive mutants, includes CDC48 [5], ORC2 [6], and PDS5 [7], showed apoptotic cell death. We speculate that all cells undergo apoptotic cell death at the nonpermissive temperature. To test this speculation, wild type cells were incubated overnight at $42^{\circ} \mathrm{C}$, a nonpermissive temperature for wild type cells. 


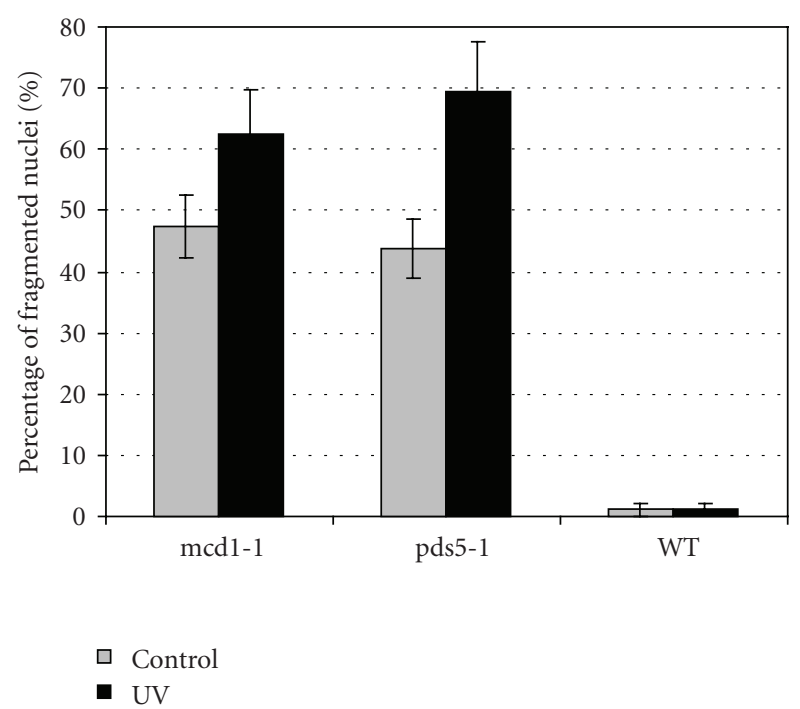

(a)

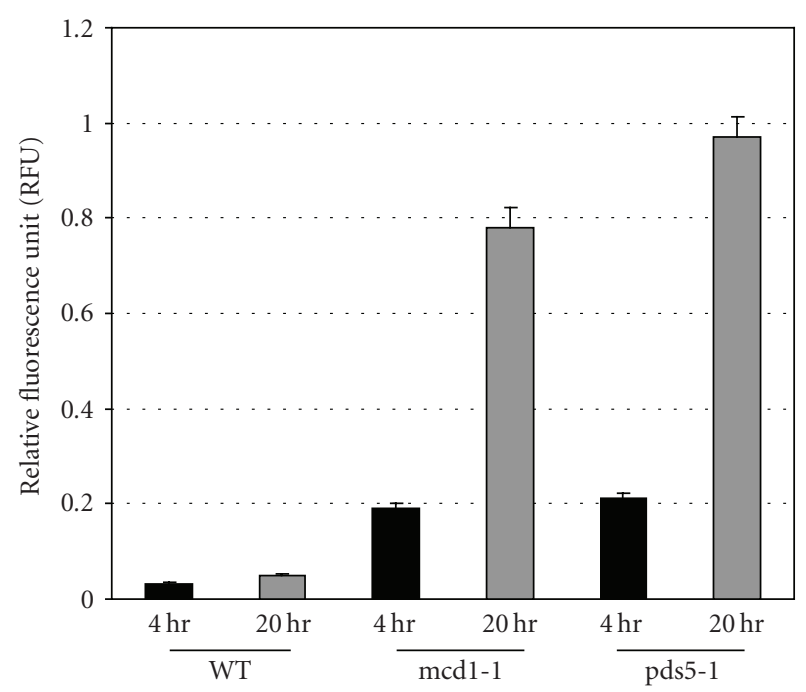

(b)

FIGURE 6: UV radiation caused increase of apoptotic cell death in mcd1-1 and pds5-1 mutants. (a) wild type, pds5-1 cells, and mcd11 cells were exposed to UV radiation $\left(150 \mathrm{~J} / \mathrm{m}^{2}\right)$ then incubated for 20 hours at $37^{\circ} \mathrm{C}$. Cells were stained with DAPI to identify the fragmented nuclei. Data are from 3 independent experiments; at least 100 cells were counted for each experiment. (b) ROS was produced in pds5-1 and mcd1-1 mutants. Wild type and the mcd11 and pds5-1mutants were exposed to UV radiation $\left(150 \mathrm{~J} / \mathrm{m}^{2}\right)$ then incubated for 2 and 18 hours at $37^{\circ} \mathrm{C}$. Dihydrorhodamine 123 (Priault et al. pages 684-91) was added into cell culture and incubated for another 2 hours, ROS production was measured using a microplate reader.

Apoptotic cell death was revealed in majority of wild-type cells. More than $90 \%$ of wild-type cells showed positive Annexin V staining, nuclei fragmentation, and chromatin condensation. About $50 \%$ of cells showed positive TUNEL staining, while none showed positive TUNEL staining at permissive temperature (Figure 8). ROS level was much

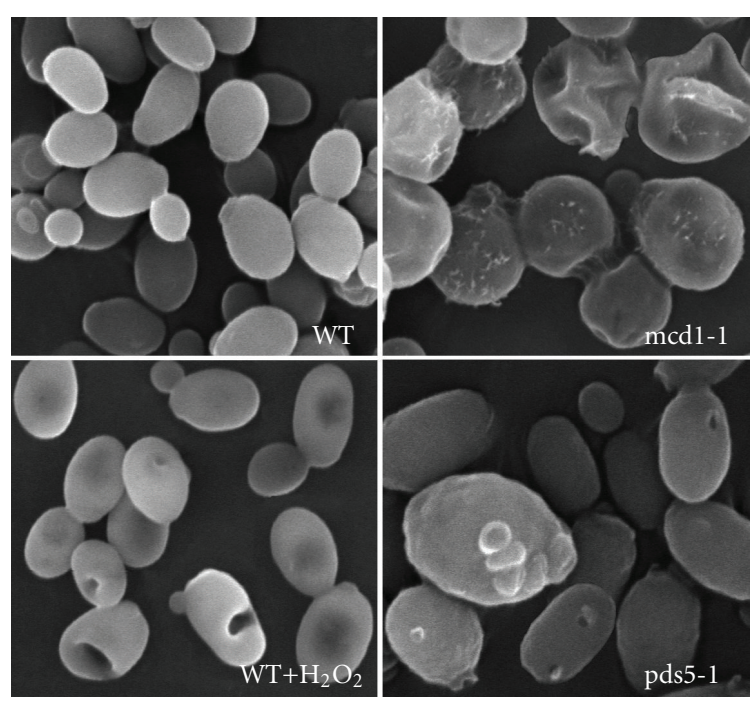

(a)

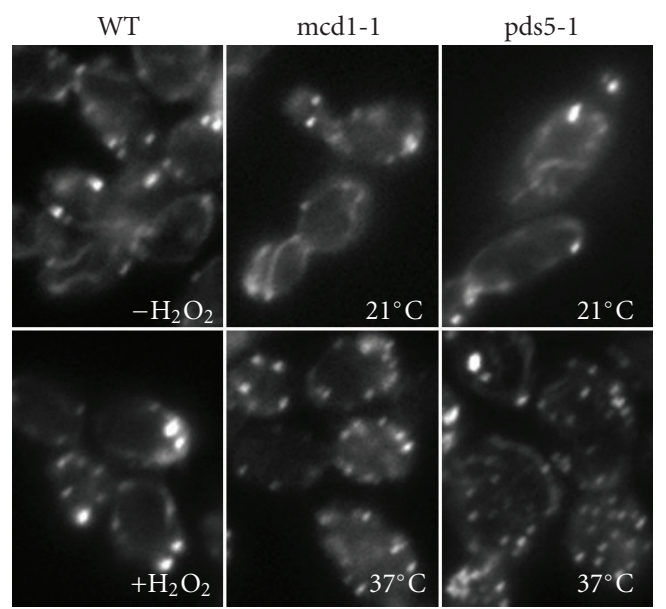

(b)

FIgURE 7: (a) Scanning electron microscopy images of wild type, $\mathrm{H}_{2} \mathrm{O}_{2}$-treated (4 hours) cells, mcd1-1 and pds5-1 cells at nonpermissive temperature for 2 hours. (b) rhodamine-phalloidin staining of actin of wild type (with or without $\mathrm{H}_{2} \mathrm{O}_{2}$ for 4 hours), mcd11 and pds51-1 mutants grown at permissive or nonpermissive temperature for 2 hours.

higher than cells grown at $30^{\circ} \mathrm{C}$. Wild type showed no significant difference from the mcd1-1 or pds5-1 mutants when both incubated at $42^{\circ} \mathrm{C}$ (data not shown). This result suggests that high temperature stress causes apoptosis in yeast and can be used as an apoptosis inducer for studying the mechanism of apoptotic cell death in yeast.

\section{Discussion}

Sister chromatid cohesin plays a crucial role in accurate chromosomal segregation in the eukaryotic cell cycle. Recent studies indicate that cohesin proteins are also involved in apoptosis. Two studies showed that the $\operatorname{Rad} 21$ of mammalian 
TABLE 5: List of differentially regulated genes that are related to mitochondria functions in time point 1 (Bold = genes appeared in both time points; ${ }^{*}=$ only those localized in mitochondria).

\begin{tabular}{|c|c|c|c|c|c|}
\hline & \multirow{2}{*}{ Gene name } & \multicolumn{3}{|c|}{ Fold change } & \multirow{2}{*}{ Description } \\
\hline & & $\mathrm{H}_{2} \mathrm{O}_{2}$ & $\operatorname{mcd} 1$ & pds5-1 & \\
\hline \multirow{17}{*}{$\begin{array}{l}\text { Localized only in } \\
\text { mitochondria }\end{array}$} & CYC7 & 13.93 & 2.64 & 9.85 & Cytochrome c isoform 2 \\
\hline & OM14 & 11.31 & 3.25 & 14.93 & Integral mitochondrial outer membrane protein \\
\hline & ALD4 & 9.19 & 2.64 & 19.70 & Mitochondrial aldehyde dehydrogenase \\
\hline & LSC2 & 8.57 & 2.30 & 9.85 & Beta subunit of succinyl-CoA ligase \\
\hline & CEM1 & 8.57 & 2.30 & 11.31 & Mitochondrial beta-keto-acyl synthase \\
\hline & STF1 & 8.57 & 2.46 & 9.85 & Involved in regulation of the mitochondrial F1F0-ATP synthase \\
\hline & RSM19 & 8.00 & 2.14 & 8.00 & Mitochondrial ribosomal protein of the small subunit \\
\hline & OM45 & 8.00 & 3.03 & 16.00 & Major constituent of the mitochondrial outer membrane \\
\hline & CYB2 & 8.00 & 4.00 & 12.13 & Cytochrome b2 (L-lactate cytochrome-c oxidoreductase) \\
\hline & YME2 & 7.46 & 2.00 & 7.46 & Integral inner mitochondrial membrane protein \\
\hline & MRPL19 & 7.46 & 2.00 & 8.57 & Mitochondrial ribosomal protein of the large subunit \\
\hline & SLM5 & 7.46 & 2.14 & 9.19 & Mitochondrial asparaginyl-tRNA synthetase \\
\hline & AEP1 & 6.96 & 2.00 & 7.46 & Required for expression of the mitochondrial OLI1 gene \\
\hline & FMP46 & 6.96 & 2.00 & 10.56 & Putative redox protein containing a thioredoxin fold \\
\hline & MBR1 & 6.96 & 3.73 & 9.85 & Involved in mitochondrial functions and stress response \\
\hline & ODC1 & 6.06 & 2.00 & 9.19 & Mitochondrial inner membrane transporter \\
\hline & GLT1 & -3.48 & -2.00 & -2.46 & NAD $(+)$-dependent glutamate synthase \\
\hline \multirow{9}{*}{$\begin{array}{l}\text { Localized in mitochondria } \\
\text { and nucleus/cytoplasm }\end{array}$} & NTH2 & 13.93 & 2.00 & 10.56 & Putative neutral trehalase \\
\hline & GCV1 & 11.31 & 2.83 & 12.13 & T subunit of the mitochondrial glycine decarboxylase complex \\
\hline & GOR1 & 9.85 & 2.00 & 10.56 & Glyoxylate reductase \\
\hline & DIA4 & 9.19 & 2.30 & 8.57 & Probable mitochondrial seryl-tRNA synthetase \\
\hline & RSF1 & 8.00 & 2.30 & 8.57 & Protein required for respiratory growth \\
\hline & YHL009W-B & 8.00 & 2.83 & 8.57 & Retrotransposon TYA Gag and TYB Pol genes \\
\hline & NTG1 & 6.96 & 2.30 & 7.46 & DNA N-glycosylase and apurinic/apyrimidinic (AP) lyase \\
\hline & ELG1 & 6.96 & 2.30 & 10.56 & Required for $\mathrm{S}$ phase progression and telomere homeostasis \\
\hline & LRG1 & -2.46 & -2.30 & -3.25 & Putative GTPase-activating protein (GAP) \\
\hline \multirow{12}{*}{ Of unknown functions } & TMA10 & 19.70 & 7.46 & 13.93 & Protein of unknown function that associates with ribosomes \\
\hline & *YPL222W & 12.13 & 2.30 & 9.85 & $\begin{array}{l}\text { The authentic, nontagged protein was localized to the } \\
\text { mitochondria. }\end{array}$ \\
\hline & *YDR379C-A & 10.56 & 2.83 & 10.56 & Hypothetical protein identified by homology. \\
\hline & UIP4 & 8.57 & 2.64 & 19.70 & Protein of unknown function that interacts with Ulplp \\
\hline & *YDR070C & 8.57 & 9.85 & 22.63 & $\begin{array}{l}\text { The authentic, nontagged protein was localized to the } \\
\text { mitochondria }\end{array}$ \\
\hline & *YOR205C & 8.00 & 2.00 & 9.85 & $\begin{array}{l}\text { The authentic, nontagged protein was localized to the } \\
\text { mitochondria }\end{array}$ \\
\hline & *YHL021C & 7.46 & 2.14 & 6.96 & $\begin{array}{l}\text { The authentic, nontagged protein was localized to the } \\
\text { mitochondria }\end{array}$ \\
\hline & *YDR332W & 7.46 & 2.64 & 11.31 & Hypothetical protein \\
\hline & YML128C & 7.46 & 6.06 & 22.63 & Protein of unknown function \\
\hline & *YJL062W-A & 6.96 & 2.14 & 8.57 & Putative protein of unknown function \\
\hline & *YNR040W & 6.96 & 2.30 & 8.57 & Hypothetical protein \\
\hline & *YNL195C & 6.96 & 3.03 & 27.86 & Hypothetical protein \\
\hline
\end{tabular}

cells was cleaved during apoptosis induced by diverse stimuli. The $\mathrm{C}$ terminal of Rad21 cleavage product was translocated to cytoplasm and caused amplification of the cell-death signal $[21,22]$. In human breast cancer cells, expression level of RAD21 is higher than normal cells. Inhibition of
RAD21 lows the survival rate of breast cancer cells and induces apoptotic cell death [24]. In S. cerevisiae, mutation of PDS5 causes apoptotic-like cell death in early meiosis [7]. When treated with $\mathrm{H}_{2} \mathrm{O}_{2}$, which causes apoptosis in yeast [3], the Mcd1 level was decreased (Yang \& Zhang, 
TABLE 6: List of differentially expressed genes that are related to mitochondria functions in time point 2, (bold = genes appeared in both time points; ${ }^{*}=$ only those localized in mitochondria).

\begin{tabular}{|c|c|c|c|c|c|}
\hline & \multirow{2}{*}{ Gene name } & \multicolumn{3}{|c|}{ Fold change } & \multirow{2}{*}{ Description } \\
\hline & & $\mathrm{H}_{2} \mathrm{O}_{2}$ & $\operatorname{mcd} 1-1$ & pds5-1 & \\
\hline \multirow{15}{*}{$\begin{array}{l}\text { Localized only in } \\
\text { mitochondria }\end{array}$} & CRC1 & 27.86 & 32.00 & 9.85 & Mitochondrial inner membrane carnitine transporter \\
\hline & PUT1 & 16.00 & 32.00 & 8.57 & Proline oxidase \\
\hline & HXT14 & 13.00 & 9.19 & 9.85 & Hexose transport \\
\hline & UBP16 & 11.31 & 2.46 & 8.57 & Ubiquitin-dependent protein catabolism \\
\hline & $\mathrm{AAC} 1$ & 11.31 & 8.00 & 8.57 & Mitochondrial inner membrane ADP/ATP translocator \\
\hline & PGS1 & 10.56 & 2.83 & 7.46 & Phosphatidylglycerolphosphate synthase \\
\hline & YHL009W-A & 10.56 & 3.48 & 9.19 & DNA-mediated transposition \\
\hline & GCV2 & 9.19 & 2.64 & 12.13 & P subunit of the mitochondrial glycine decarboxylase complex \\
\hline & AEP1 & 9.19 & 3.48 & 11.31 & Protein biosynthesis \\
\hline & HTD2 & 9.19 & 3.73 & 8.00 & Mitochondrial 3-hydroxyacyl-thioester dehydratase \\
\hline & HMI1 & 8.57 & 2.46 & 6.96 & Mitochondrial ATP-dependent DNA helicase \\
\hline & ARG2 & 7.46 & 2.64 & 9.85 & Acetylglutamate synthase \\
\hline & GLT1 & -2.64 & -3.48 & -2.64 & $\mathrm{NAD}(+)$-dependent glutamate synthase \\
\hline & ILV5 & -3.03 & -2.14 & -3.48 & Acetohydroxyacid reductoisomerase \\
\hline & POR2 & -3.03 & -2.00 & -2.00 & Ion transport \\
\hline \multirow{17}{*}{$\begin{array}{l}\text { Localized in mitochondria } \\
\text { and nucleus/cytoplasm }\end{array}$} & JJJ1 & 16.00 & 2.14 & 21.11 & endocytosis \\
\hline & HSF1 & 12.13 & 3.73 & 9.19 & Trimeric heat shock transcription factor \\
\hline & SPC105 & 9.85 & 3.03 & 7.46 & Protein required for accurate chromosome segregation \\
\hline & GCV1 & 9.85 & 8.00 & 8.00 & T subunit of the mitochondrial glycine decarboxylase complex \\
\hline & NTH2 & 9.19 & 5.28 & 9.19 & Putative neutral trehalase \\
\hline & VPS15 & 8.57 & 2.00 & 7.46 & Myristoylated serine/threonine protein kinase \\
\hline & VPS54 & 8.57 & 2.00 & 8.00 & Component of the Golgi-associated retrograde protein complex \\
\hline & PTC5 & 8.57 & 2.00 & 8.57 & Mitochondrially localized type $2 \mathrm{C}$ protein phosphatase \\
\hline & LAS1 & 8.57 & 2.00 & 12.13 & Essential nuclear protein possibly involved in morphogenesis \\
\hline & BIR1 & 8.57 & 2.46 & 8.57 & Cell cycle, anti-apoptotic \\
\hline & ELG1 & 8.57 & 2.46 & 12.13 & Required for $\mathrm{S}$ phase progression and telomere homeostasis \\
\hline & NTG1 & 8.57 & 3.48 & 7.46 & DNA N-glycosylase and apurinic/apyrimidinic (AP) lyase \\
\hline & AFT2 & 8.57 & 3.73 & 8.57 & Iron-regulated transcriptional activator \\
\hline & RIS1 & 8.00 & 2.46 & 7.46 & Member of the SWI/SNF family of DNA-dependent ATPases \\
\hline & GYP1 & 8.00 & 3.03 & 8.57 & Vesicle-mediated transport \\
\hline & SUR7 & -2.83 & -2.14 & -3.48 & Putative integral membrane protein \\
\hline & MRH1 & -2.83 & -2.00 & -2.83 & Protein that localizes primarily to the plasma membrane \\
\hline \multirow{8}{*}{ Of unknown functions } & *YNL130C-A & 18.38 & 8.57 & 12.13 & Protein of unknown function \\
\hline & *YBR047W & 13.93 & 4.29 & 8.57 & Protein of unknown function \\
\hline & *YLR346C & 11.31 & 11.31 & 14.93 & Protein of unknown function \\
\hline & *YLR253W & 9.85 & 2.46 & 8.00 & Protein of unknown function \\
\hline & TOF2 & 9.85 & 3.03 & 13.93 & Protein of unknown function \\
\hline & *YDR332W & 9.85 & 4.92 & 7.46 & Hypothetical protein \\
\hline & *YGL226W & 8.57 & 2.30 & 8.00 & Protein of unknown function \\
\hline & *YOR305W & 8.00 & 2.00 & 9.19 & Protein of unknown function \\
\hline
\end{tabular}

unpublished data), suggesting a role of MCD1 in peroxideinduced apoptosis. Our current study further suggests that certain cohesin proteins, such as Mcd1 or Pds5, are required for cell proliferation. Malfunction of these cohesin proteins causes apoptotic cell death in yeast, as well as in mammalian cells.

Yeast cells show an apoptotic phenotype under a variety of environmental stresses, such as hydrogen peroxide [3, 4]. 
TABLE 7: List of differentially regulated genes that are related to cell cycle in time point 2 (note that all genes are upregulated).

\begin{tabular}{|c|c|c|c|c|}
\hline \multirow{2}{*}{ Gene name } & \multicolumn{3}{|c|}{ Fold change } & \multirow{2}{*}{ Description } \\
\hline & $\mathrm{H}_{2} \mathrm{O}_{2}$ & $\operatorname{mcd} 1-1$ & pds5-1 & \\
\hline CSM4 & 25.99 & 13.00 & 13.93 & Meiotic chromosome segregation \\
\hline REC8 & 10.10 & 14.90 & 8.60 & Meiotic sister chromatid cohesion \\
\hline SPR3 & 18.38 & 18.38 & 13.00 & Cellular morphogenesis during conjugation with cellular fusion \\
\hline REC114 & 17.15 & 4.92 & 22.63 & Meiotic recombination \\
\hline MER1 & 17.15 & 2.83 & 18.38 & Regulation of nuclear mRNA splicing \\
\hline CST9 & 13.93 & 4.00 & 14.93 & Synaptonemal complex formation \\
\hline SWI4 & 13.93 & 3.73 & 9.19 & G1/S transition of mitotic cell cycle \\
\hline SPS4 & 13.00 & 4.59 & 7.46 & DNA metabolism \\
\hline OKP1 & 13.00 & 2.14 & 8.57 & Chromosome segregation \\
\hline SFI1 & 12.13 & 3.73 & 11.31 & G2/M transition of mitotic cell cycle \\
\hline EPL1 & 12.13 & 3.73 & 8.57 & Regulation of transcription from RNA polymerase II promoter \\
\hline MPS3 & 12.13 & 2.83 & 10.56 & Nuclear migration during conjugation with cellular fusion \\
\hline SCC4 & 12.13 & 2.30 & 9.19 & Double-strand break repair \\
\hline MAD2 & 12.13 & 2.00 & 11.31 & Mitotic spindle checkpoint \\
\hline FKH2 & 11.31 & 3.48 & 13.00 & G2/M-specific transcription in mitotic cell cycle \\
\hline ISC10 & 11.31 & 2.64 & 14.93 & Protein required for sporulation \\
\hline MPC54 & 10.56 & 21.11 & 17.15 & Spore wall assembly \\
\hline DMA2 & 10.56 & 4.29 & 9.85 & Establishment of mitotic spindle orientation \\
\hline REC107 & 10.56 & 3.25 & 9.85 & Meiotic recombination \\
\hline IBD2 & 10.56 & 3.03 & 17.15 & Mitotic spindle checkpoint \\
\hline MPT5 & 10.56 & 2.64 & 12.13 & Reentry into mitotic cell cycle after pheromone arrest \\
\hline MAD3 & 10.56 & 2.64 & 9.85 & Mitotic spindle checkpoint \\
\hline CLN3 & 10.56 & 2.30 & 9.85 & G1 cyclin involved in cell cycle progression \\
\hline REC104 & 9.85 & 14.93 & 9.85 & Meiotic recombination \\
\hline KEL2 & 9.85 & 5.66 & 7.46 & Regulation of exit from mitosis \\
\hline KAR3 & 9.85 & 4.92 & 10.56 & Mitotic sister chromatid cohesion \\
\hline BCK2 & 9.85 & 3.25 & 9.19 & Regulation of progression through cell cycle \\
\hline RTT101 & 9.85 & 2.83 & 9.85 & Negative regulation of DNA transposition \\
\hline SLK19 & 9.85 & 2.46 & 7.46 & Meiosis/mitotic spindle organization \\
\hline LRS4 & 9.85 & 2.30 & 10.56 & Protein involved in rDNA silencing \\
\hline MND1 & 9.19 & 68.59 & 6.96 & Meiotic recombination \\
\hline HOP2 & 9.19 & 4.92 & 14.93 & Meiotic recombination \\
\hline KIP1 & 9.19 & 3.03 & 7.46 & Mitotic spindle assembly and chromosome segregation \\
\hline SLD2 & 9.19 & 2.46 & 9.19 & DNA strand elongation \\
\hline TFB3 & 9.19 & 2.14 & 9.19 & Regulation of transcription \\
\hline TAF2 & 9.19 & 2.14 & 9.19 & G1-specific transcription in mitotic cell cycle \\
\hline SPO11 & 8.57 & 7.46 & 8.57 & DNA metabolism \\
\hline PRP46 & 8.57 & 3.73 & 11.31 & Nuclear mRNA splicing \\
\hline UME6 & 8.57 & 3.25 & 9.85 & G2/M transition of mitotic cell cycle \\
\hline ELG1 & 8.57 & 2.46 & 12.13 & Regulation of DNA transposition \\
\hline CDC45 & 8.57 & 2.46 & 9.19 & Prereplicative complex formation and maintenance \\
\hline BIR1 & 8.57 & 2.46 & 8.57 & Mitotic spindle elongation \\
\hline CHL1 & 8.57 & 2.46 & 8.00 & Mitotic sister chromatid cohesion \\
\hline SGO1 & 8.57 & 2.30 & 8.57 & Sister chromatid segregation \\
\hline SLD3 & 8.57 & 2.14 & 9.19 & DNA unwinding during replication \\
\hline CEF1 & 8.00 & 3.73 & 10.56 & Nuclear mRNA splicing \\
\hline MPS1 & 8.00 & 3.25 & 8.57 & Mitotic spindle assembly \\
\hline SET3 & 8.00 & 3.25 & 7.46 & Histone deacetylation \\
\hline SPC72 & 8.00 & 2.64 & 8.00 & Mitotic spindle elongation \\
\hline CDC26 & 8.00 & 2.46 & 18.38 & Protein ubiquitination \\
\hline
\end{tabular}


TABle 7: Continued.

\begin{tabular}{|c|c|c|c|c|}
\hline Gene name & \multicolumn{2}{|c|}{ Fold change } & pds5-1 & Description \\
\hline MCM22 & 8.00 & 2.30 & 9.85 & Chromosome segregation \\
\hline MMS4 & 8.00 & 2.00 & 8.00 & Involvement in recombination and DNA repair \\
\hline NIP100 & 7.46 & 4.92 & 9.85 & Establishment of mitotic spindle orientation \\
\hline DBF4 & 7.46 & 3.25 & 9.19 & Regulation of DNA replication \\
\hline MEC3 & 7.46 & 2.83 & 6.96 & DNA damage checkpoint \\
\hline PIN4 & 7.46 & 2.46 & 9.19 & G2/M transition of mitotic cell cycle \\
\hline GIC2 & 7.46 & 2.14 & 9.19 & Regulation of exit from mitosis \\
\hline IME1 & 6.96 & 17.15 & 16.00 & Regulation of transcription \\
\hline LCD1 & 6.96 & 3.48 & 7.46 & DNA damage checkpoint \\
\hline ULP1 & 6.96 & 2.46 & 7.46 & Ubl (ubiquitin-like protein)-specific protease \\
\hline YOR019W & 13.93 & 8.57 & 11.31 & Protein of unknown function \\
\hline SPR6 & 10.56 & 2.30 & 9.19 & Protein of unknown function \\
\hline
\end{tabular}

Temperature shift in several temperature-sensitive mutants includes CDC48 [5], ORC2 [6], and PDS5 [7], and also shows apoptotic cell death. Our current study suggests that the cell death caused by nonpermissive temperature is due to the internal stress response (ISR), compared to external stress response (ESR). A common feature shared by the ISR and ESR is response to stimulus, including response to DNA damage, oxidative stress, and heat. Our data also suggest that ESR may become ISR that ultimately causes the cell death. Since all the genes in the temperature sensitive mutants are essential genes, it would be interesting to see if cell death caused by the malfunction of all essential genes is apoptotic and due to ISR. Another commonality of the yeast cell death is the apoptotic nature of cell death at nonpermissive temperature, because all yeast strains, including the wild type die at their nonpermissive temperature, that is, above $37^{\circ} \mathrm{C}$. Our result shows that even the wild-type cells undergo apoptotic cell death at their nonpermissive temperature (Figure 8).

Several studies have shown that DNA damage stimulates apoptosis in budding yeast. Mutation in CDC13, for example, triggers apoptotic cell death due to the accumulation of DNA damage [35]. UV radiation also induces some features of apoptosis [36]. These findings suggest that yeast may share some of the apoptotic pathways induced by DNA damage in mammals, especially those p53-independent pathways. Sister chromatid cohesin also appears to be involved in DNA repair. In fact, the cohesin subunit Rad21 was first identified in Schizosaccharomyces pombe by its sensitivity to UV or ionizing radiation, suggesting a role in DNA repair [37]. A recent study showed that downregulation of RAD21 impaired DNA double strand break repair and cells were more sensitive to etoposide and bleomycin, which induce double strand breaks [24]. In fission yeast, mutants of PDS5 lost the proliferative ability after arrest in $G_{2}$ and were hypersensitive to DNA damage [27]. Our current study further confirms that DNA damage plays an important role in yeast cell death due to the fact that (1) a large amount of genes related to DNA damage repair are differentially expressed during apoptosis by either $\mathrm{H}_{2} \mathrm{O}_{2}$ treatment or by mutation of the cohesin protein Mcd1 or Pds5; and (2) UV radiation caused significant increase of cell death in mcd11 and pds5-1 mutants. We speculate that this defect in DNA repair may trigger the signaling pathway that ultimately leads to the cell death.

\section{Materials and Methods}

\subsection{Yeast Strains and Culture Conditions}

The wild-type strain used in this study is MATa ADE2 ade5 can $1^{R}$ CYH2 $2^{s}$ his7 2 leu1-d lys2-1 met13-d trp1-63 tyr1-1 ura3-13. Plasmids of mcd1-1 and pds5-1 were provided by Dr. V Guacci and transformed into the wild-type strain. The construction and characterization of both mcd1-1 and pds5-1 were described previously $[15,38]$. Both mcd11 and pds5-1 are temperature sensitive mutants, growing normally at $21^{\circ} \mathrm{C}$, but unable to grow at $37^{\circ} \mathrm{C}$. Cells were grown in YPDA medium (1\% Yeast Extract, 2\% Peptone, $2 \%$ Dextrose, $0.001 \%$ Adenine) on a mechanical shaker at specified temperature.

\subsection{Annexin V Staining}

Exposed phosphatidylserine was detected by Alexa Fluor488 conjugated annexin V (Invitrogen, Inc.). $1 \times 10^{5}$ yeast cells were collected and washed twice with sorbitol buffer ( $0.8 \mathrm{M}$ sorbitol, $2 \%$ potassium acetate, $\mathrm{pH} 7.0$ ), resuspended in sorbitol buffer containing $10 \mathrm{mM}$ dithiothreitol for 10 minutes, then digested with $0.4 \mathrm{mg} \mathrm{mL}^{-1}$ Zymolyase $100 \mathrm{~T}$ (ICN Biomedicals, Inc.) for 30 minutes. Cells were then harvested and resuspended in $50 \mu \mathrm{L}$ binding buffer $(10 \mathrm{mM}$ HEPES, $140 \mathrm{mM} \mathrm{NaCl}, 2.5 \mathrm{mM} \mathrm{CaCl} 2,1.2 \mathrm{M}$ Sorbitol, $\mathrm{pH}$ 7.4). $4 \mu \mathrm{L}$ of annexin $\mathrm{V}$ conjugate, $2 \mu \mathrm{l}$ of $1 \mu \mathrm{g} \mathrm{mL}^{-1}$ propidium iodide (PI) were added to the cell suspension and incubated for 20 minutes at room temperature in dark. Cells were rinsed with binding buffer, mounted under a coverslip with antifading medium $(0.1 \mathrm{M}$ propyl gallate, $50 \%$ 
TABLE 8: List of differentially expressed genes in all three groups that are related to cell wall.

\begin{tabular}{cccccl}
\hline & Gene name & \multicolumn{3}{c}{ Fold change } & Description \\
& & $\mathrm{H}_{2} \mathrm{O}_{2}$ & mcd1-1 & pds5-1 & \\
\hline \multirow{3}{*}{ Time point 1 } & SSP2 & 10.56 & 3.03 & 10.56 & Spore wall assembly \\
& SPI1 & 9.19 & 5.66 & 19.70 & Cell-wall protein of unknown function \\
& FIG2 & 8.57 & 3.25 & 8.57 & Cellular morphogenesis \\
& YGP1 & 8.00 & 3.03 & 10.56 & Amino acid metabolism (response to stress/nutrient) \\
& GAS4 & 7.46 & 2.14 & 7.46 & Carbohydrate metabolism \\
& PHO5 & -2.46 & -2.14 & -2.00 & Phosphate metabolism \\
Time point 2 & TIR1 & -2.83 & -2.64 & -2.00 & Cell-wall mannoprotein of the Srp1p/Tip1p family \\
& SPR3 & 18.38 & 18.38 & 13.00 & Cell-wall organization and biogenesis \\
& SSP2 & 16.00 & 9.19 & 9.85 & Spore-wall assembly \\
& GAS4 & 11.31 & 4.59 & 8.57 & Carbohydrate metabolism \\
& LRE1 & 6.96 & 2.14 & 7.46 & Cell-wall organization and biogenesis \\
\hline
\end{tabular}

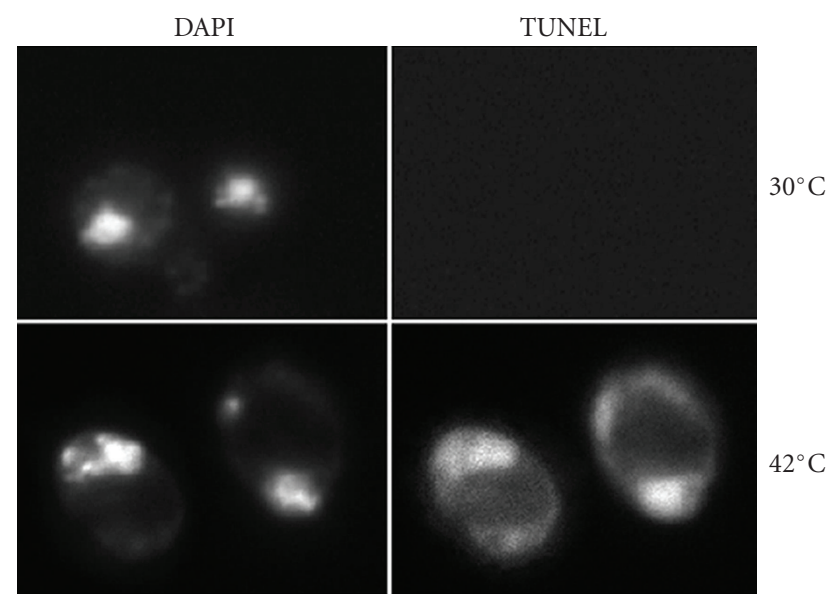

Figure 8: TUNEL staining of wild-type cells at permissive $\left(30^{\circ} \mathrm{C}\right)$ and nonpermissive temperature $\left(42^{\circ} \mathrm{C}\right)$, showing DNA breaks at nonpermissive temperature.

glycerol in PBS) containing $0.5 \mu \mathrm{g} \mathrm{mL}^{-1}$ 4', 6-diamidino-2phenylindole (DAPI). A Nikon-TE300-inverted microscope, equipped with a Cascade 650-cooled CCD monochrome camera (Roper Scientific) was used for image acquisition.

\subsection{Terminal Deoxynucleotidyl Transferase-Mediated DUTP Nick End Labeling (TUNEL) Assay}

DNA breaks were detected by the ApoAlert DNA Fragmentation Assay Kit (Clontech Laboratories, Inc.) following the manufacturer's user manual. Briefly, yeast cells were digested with $0.1 \mathrm{mg} / \mathrm{mL}$ Zymolyase $100 \mathrm{~T}$ for 5 minutes, then spread on polylysine-coated slides. The slides were fixed with $4 \%$ paraformaldehyde for 30 minutes, and then rinsed with PBS. Cells were permeabilized by $0.2 \%$ Triton X-100 in PBS for 5 minutes on ice. DNA breaks were detected by
TUNEL reaction using fluorescein conjugated dUTP. Positive control is conducted by incubation of cells with DNase I and negative control by omitting the terminal deoxynucleotidyl transferase.

\subsection{Transmission Electron Microscopy}

TEM sample preparation was conducted as described previous [34]. Briefly, cells were fixed with $2.5 \%$ (v/v) glutaraldehyde in phosphate buffered saline (PBS) $(\mathrm{pH}=7.2)$ for 40 minutes at room temperature. Cells were further fixed with $2 \%$ potassium permanganate in water for 1 hour at room temperature, then stained with $2 \%$ uranyl acetate for 90 minutes. Fixed cells were dehydrated with 30\%, 50\%, 75\%, $85 \%, 95 \%$, and $100 \%$ ethanol, then embedded in Spurr resin (Electron Microscopy Sciences, Pa). $60 \mathrm{~nm}$ ultrathin sections were cut with a diamond knife, stained with lead citrate for 30 minutes, and examined using a Hitachi H-7000 electron microscope, equipped with a high-resolution $(4 \mathrm{~K} \times 4 \mathrm{~K})$ cooled CCD digital camera (Gatan, Inc., Pa, USA).

\subsection{Detection of Reactive Oxygen Species (ROS)}

ROS was detected with dihydrorhodamine 123 (Sigma Chemical Co., Mo, USA). Dihydrorhodamine $123(50 \mu \mathrm{M}$, final concentration) was added into cell culture and incubated for 2 hours. Cells were then mounted on microscope slides and viewed with fluorescence microscope using a rhodamine optical filter. A GEMINI XS fluorescence microplate reader (Molecular Devices, $\mathrm{CA}$ ) was used for the quantitative measurement of ROS. $\mathrm{H}_{2} \mathrm{O}_{2}$ treated cells, mcd1-1, pds51 mutants were stained with Dihydrorhodamine 123 and placed in a 96 well plate. Fluorescence reading was perfumed with the wavelength of $570 \mathrm{~nm}$ for excitation and $615 \mathrm{~nm}$ for emission. 


\subsection{Microarray Analysis}

For pds5-1 cells and mcd1-1 mutants, cells were inoculated into fresh YPDA medium and cultured at $21^{\circ} \mathrm{C}$ overnight to a density of $1.0 \times 10^{7}$ cells $/ \mathrm{ml}$, then shifted to $37^{\circ} \mathrm{C}$ for 2 or 12 hours and harvested for RNA isolation. The 2- and 12-hour time points were chosen because these time points represented cells with an apoptosis rate of $1-5 \%$ and $50-$ $60 \%$, respectively. These two time points were referred as time point 1 ( 2 hours) and time point 2 (12 hours). For control, wild-type cells were treated as the same as above and RNA was isolated at the two same time points.

$\mathrm{H}_{2} \mathrm{O}_{2}$-treated wild-type cells were used as a positive control. Wild-type cells were inoculated into fresh medium and incubated at $37^{\circ} \mathrm{C}$ until the cultures reached a density of $5 \times 10^{6}$ cells $/ \mathrm{mL}$. $5 \mathrm{mM} \mathrm{H} \mathrm{H}_{2} \mathrm{O}_{2}$ was added to the culture and the cells were continually cultured at $37^{\circ} \mathrm{C}$ for 4 or 10 hours before harvested for total RNA isolation. The 4 - and 10-hour treatment of $\mathrm{H}_{2} \mathrm{O}_{2}$ represents an apoptosis rate of 3$5 \%$ and $50-60 \%$, respectively, and as referred to time point 1 and time point 2 , corresponding to mcd1-1 and pds5-1. The control sample was treated as same as above, except with the omission of $\mathrm{H}_{2} \mathrm{O}_{2}$.

Total RNA was extracted using the enzymatic lysis protocol of Qiagen RNeasy minikits (Qiagen; Valencia, Calif) with the following modification. Buffer Y1 was replaced with sorbitol buffer $(0.8 \mathrm{M}$ sorbitol, $2 \%$ potassium acetate, $\mathrm{pH} 7.0$ ). $0.5 \mathrm{mg} / \mathrm{mL}$ (final concentration) of Zymolyase$100 \mathrm{~T}$ (MP Biomedicals, Aurora, Ohio) was used for cellwall removal and the enzyme digestion time was 5 minutes. RNA labeling and hybridization procedures were performed according to protocols from the Microarray Core at the University of Colorado Health Science Center.

At each time point, total RNA was extracted from 5$10 \times 10^{7}$ cells using 2 Qiagen columns. The quality of the purified total RNA was evaluated by Agilent bioanalyzer and NanoDrop Spectrophotometer. $2.5 \mu \mathrm{g}$ of high-quality total RNA was used as template for cDNA synthesis by reverse transcription. Affymetrix one-cycle cDNA Synthesis Kit, cDNA Sample Cleanup Module, and IVT Labeling Kit were used to produce biotinylated cRNA target. The Agilent bioanalyzer and NanoDrop Spectrophotometer were used to determine the cRNA yield, purity, and size distribution. Approximately, $20 \mu \mathrm{g}$ of cRNA were used for fragmentation with the buffer from Affymetrix Hybridization Control Kit. The fragmented biotin-labeled cRNA was quantitated, and hybridized to the Affymetrix GeneChip Yeast Genome 2.0 Array, which includes approximately 5744 probe sets for 5 841 of the 5845 genes present in S. cerevisiae.

Microarray data was first analyzed using Affymetrix's GeneChip Operating Software. The expression level of the cohesin mutants and $\mathrm{H}_{2} \mathrm{O}_{2}$-treated cells at different time points was compared with that of the corresponding control cells, using the software's default parameters (Alpha1 = 0.05 , Alpha $=0.065$, Tau $=0.015$, Gamma1H $=0.002$, Gamma1L $=0.002$, Gamma2H $=0.002667$, Gamma2L $=$ 0.002667 , Perturbation $=1.1$ ). A call to each gene indicating the change in transcript level between the baseline (control) and the experiment array was assigned with one of the following values: Increase (I), Decrease (D), No Change (NC), Marginal Increase (MI), or Marginal Decrease (MD). Genes with a value of $\mathrm{NC}, \mathrm{MI}$, or MD were all regarded as no change of transcription level, and only the genes with a value I or D were selected. Fold change of the differentially expressed genes was calculated based on the signal-log ratio. Only the genes with a fold change equal to or greater than 2 were selected to ensure the gene expression was truly differential. Microarray data were derived from two independent experiments. Values were average of the twoindependent experiments

\subsection{Scanning Electron Microscopy (SEM)}

Cells at time point 1 were fixed with $2.5 \%$ glutaraldehyde in phosphate buffer ( $\mathrm{pH} 7.3$ ), then dehydrated with ethanol (30, $50,75,85,95,100 \%, 5$ minutes each). Cells were dried with a critical point dryer; sputter coated with gold, and examined using a JEOL JSM5800LV SEM, operated at $20 \mathrm{Kv}$.

\subsection{Rhodamine-Phalloidin Staining of Actin}

Cells at time point 1 were fixed in PBS buffer with $4 \%$ formaldehyde for 1 hour. After washing with PBS buffer three times, fixed cells were resuspended in $1 \mathrm{~mL}$ PBS containing $1 \%$ Triton X-100 and incubated at room temperature for 3 minutes for cell permeabilization. Permeabilized cells were washed with PBS buffer, resuspended in $20 \mu$ l rhodaminephalloidin (Invitrogen) (final concentration $=160 \mathrm{nM}$ ) for 1 hour. Cells were mounted on a glass slide and viewed with a rhodamine filter.

\section{Conclusion}

Our data suggests that the cell death caused by mutation of MCD1 or PDS5 is due to the internal stress response,contrasting to the environmental or external stress response induced by external stimuli, such as hydrogen peroxide. A common feature shared by the internal stress response and external stress response is the response to stimulus, including response to DNA damage, mitochondria functions, and oxidative stress, which play an important role in yeast apoptotic cell death.

\section{Acknowledgments}

This research is supported by the National Institutes of Health, Institute for Research Resources, grant P20 RR15640 of the Neuroscience Center of Biomedical Research Excellence, and NIH Grant no. P20 RR016474 from the INBRE Program of the National Center for Research Resources.

\section{References}

[1] S. Büttner, T. Eisenberg, E. Herker, D. Carmona-Gutierrez, G. Kroemer, and F. Madeo, "Why yeast cells can undergo apoptosis: death in times of peace, love, and war," Journal of Cell Biology, vol. 175, no. 4, pp. 521-525, 2006. 
[2] F. Madeo, E. Herker, S. Wissing, H. Jungwirth, T. Eisenberg, and K.-U. Fröhlich, "Apoptosis in yeast," Current Opinion in Microbiology, vol. 7, no. 6, pp. 655-660, 2004.

[3] F. Madeo, E. Fröhlich, M. Ligr, et al., "Oxygen stress: a regulator of apoptosis in yeast," Journal of Cell Biology, vol. 145, no. 4, pp. 757-767, 1999.

[4] P. Ludovico, M. J. Sousa, M. T. Silva, C. Leão, and M. CôrteReal, "Saccharomyces cerevisiae commits to a programmed cell death process in response to acetic acid," Microbiology, vol. 147, no. 9, pp. 2409-2415, 2001.

[5] F. Madeo, E. Fröhlich, and K.-U. Fröhlich, "A yeast mutant showing diagnostic markers of early and late apoptosis," Journal of Cell Biology, vol. 139, no. 3, pp. 729-734, 1997.

[6] M. Weinberger, L. Ramachandran, L. Feng, et al., "Apoptosis in budding yeast caused by defects in initiation of DNA replication," Journal of Cell Science, vol. 118, no. 15, pp. 35433553, 2005.

[7] Q. Ren, H. Yang, M. Rosinski, et al., "Mutation of the cohesin related gene PDS5 causes cell death with predominant apoptotic features in Saccharomyces cerevisiae during early meiosis," Mutation Research, vol. 570, no. 2, pp. 163-173, 2005.

[8] F. Madeo, E. Herker, C. Maldener, et al., "A caspase-related protease regulates apoptosis in yeast," Molecular Cell, vol. 9, no. 4, pp. 911-917, 2002.

[9] M. A. S. Khan, P. B. Chock, and E. R. Stadtman, "Knockout of caspase-like gene, YCA1, abrogates apoptosis and elevates oxidized proteins in Saccharomyces cerevisiae," Proceedings of the National Academy of Sciences of the United States of America, vol. 102, no. 48, pp. 17326-17331, 2005.

[10] S. Wissing, P. Ludovico, E. Herker, et al., "An AIF orthologue regulates apoptosis in yeast," Journal of Cell Biology, vol. 166, no. 7, pp. 969-974, 2004.

[11] F. Uhlmann, "The mechanism of sister chromatid cohesion," Experimental Cell Research, vol. 296, no. 1, pp. 80-85, 2004.

[12] T. Hirano, "Chromosome cohesion, condensation, and separation," Annual Review of Biochemistry, vol. 69, pp. 115-144, 2000.

[13] D. P. Moore and T. L. Orr-Weaver, "Chromosome segregation during meiosis: building an unambivalent bivalent," Current Topics in Developmental Biology, vol. 37, pp. 263-299, 1998.

[14] A. Tóth, R. Ciosk, F. Uhlmann, M. Galova, A. Schleiffer, and K. Nasmyth, "Yeast cohesin complex requires a conserved protein, Ecolp (Ctf7), to establish cohesion between sister chromatids during DNA replication," Genes \& Development, vol. 13, no. 3, pp. 320-333, 1999.

[15] T. Hartman, K. Stead, D. Koshland, and V. Guacci, "Pds5p is an essential chromosomal protein required for both sister chromatid cohesion and condensation in Saccharomyces cerevisiae," Journal of Cell Biology, vol. 151, no. 3, pp. 613-626, 2000.

[16] K. Stead, C. Aguilar, T. Hartman, M. Drexel, P. Meluh, and V. A. Guacci, "Pds5p regulates the maintenance of sister chromatid cohesion and is sumoylated to promote the dissolution of cohesion," Journal of Cell Biology, vol. 163, no. 4, pp. 729-741, 2003.

[17] R. V. Skibbens, L. B. Corson, D. Koshland, and P. Hieter, "Ctf7p is essential for sister chromatid cohesion and links mitotic chromosome structure to the DNA replication machinery," Genes \& Development, vol. 13, no. 3, pp. 307-319, 1999.

[18] R. Ciosk, M. Shirayama, A. Shevchenko, et al., "Cohesin's binding to chromosomes depends on a separate complex consisting of Scc2 and Scc4 proteins," Molecular Cell, vol. 5, no. 2, pp. 243-254, 2000.

[19] S. Panizza, T. Tanaka, A. Hochwagen, F. Eisenhaber, and K. Nasmyth, "PDS5 cooperates with cohesion in maintaining sister chromatid cohesion," Current Biology, vol. 10, no. 24, pp. 1557-1564, 2000.

[20] Z. Zhang, Q. Ren, H. Yang, et al., "Budding yeast PDS5 plays an important role in meiosis and is required for sister chromatid cohesion," Molecular Microbiology, vol. 56, no. 3, pp. 670-680, 2005.

[21] F. Chen, M. Kamradt, M. Mulcahy, et al., "Caspase proteolysis of the cohesin component RAD21 promotes apoptosis," Journal of Biological Chemistry, vol. 277, no. 19, pp. 1677516781, 2002.

[22] D. Pati, N. Zhang, and S. E. Plon, "Linking sister chromatid cohesion and apoptosis: role of Rad21," Molecular and Cellular Biology, vol. 22, no. 23, pp. 8267-8277, 2002.

[23] K. P. Porkka, T. L. J. Tammela, R. L. Vessella, and T. Visakorpi, "RAD21 and KIAA0196 at 8q24 are amplified and overexpressed in prostate cancer," Genes, Chromosomes and Cancer, vol. 39, no. 1, pp. 1-10, 2004.

[24] J. M. Atienza, R. B. Roth, C. Rosette, et al., "Suppression of $R A D 21$ gene expression decreases cell growth and enhances cytotoxicity of etoposide and bleomycin in human breast cancer cells," Molecular Cancer Therapeutics, vol. 4, no. 3, pp. 361-368, 2005.

[25] A. P. Gasch, P. T. Spellman, C. M. Kao, et al., "Genomic expression programs in the response of yeast cells to environmental changes," Molecular Biology of the Cell, vol. 11, no. 12, pp. 4241-4257, 2000.

[26] A. R. Lehmann, "The role of SMC proteins in the responses to DNA damage," DNA Repair, vol. 4, no. 3, pp. 309-314, 2005.

[27] S.-W. Wang, R. L. Read, and C. J. Norbury, "Fission yeast PDS5 is required for accurate chromosome segregation and for survival after DNA damage or metaphase arrest," Journal of Cell Science, vol. 115, no. 3, pp. 587-598, 2002.

[28] D. van Heemst, F. James, S. Pöggeler, V. Berteaux-Lecellier, and D. Zickler, "Spo76p is a conserved chromosome morphogenesis protein that links the mitotic and meiotic programs," Cell, vol. 98, no. 2, pp. 261-271, 1999.

[29] T. Eisenberg, S. Büttner, G. Kroemer, and F. Madeo, "The mitochondrial pathway in yeast apoptosis," Apoptosis, vol. 12, no. 5, pp. 1011-1023, 2007.

[30] J. M. Hardwick and W.-C. Cheng, "Mitochondrial programmed cell death pathways in yeast," Developmental Cell, vol. 7, no. 5, pp. 630-632, 2004.

[31] P. Ludovico, F. Rodrigues, A. Almeida, M. T. Silva, A. Barrientos, and M. Côrte-Real, "Cytochrome $c$ release and mitochondria involvement in programmed cell death induced by acetic acid in Saccharomyces cerevisiae," Molecular Biology of the Cell, vol. 13, no. 8, pp. 2598-2606, 2002.

[32] R. Nestelbacher, P. Laun, and M. Breitenbach, "Images in experimental gerontology. A senescent yeast mother cell," Experimental Gerontology, vol. 34, no. 7, pp. 895-896, 1999.

[33] P. Laun, L. Ramachandran, S. Jarolim, et al., "A comparison of the aging and apoptotic transcriptome of Saccharomyces cerevisiae," FEMS Yeast Research, vol. 5, no. 12, pp. 1261-1272, 2005.

[34] H. Yang, Q. Ren, and Z. Zhang, "Chromosome or chromatin condensation leads to meiosis or apoptosis in stationary yeast (Saccharomyces cerevisiae) cells," FEMS Yeast Research, vol. 6, no. 8, pp. 1254-1263, 2006. 
[35] H. Qi, T.-K. Li, D. Kuo, A. Nur-E-Kamal, and L. F. Liu, "Inactivation of Cdc13p triggers MEC1-dependent apoptotic signals in yeast," Journal of Biological Chemistry, vol. 278, no. 17, pp. 15136-15141, 2003.

[36] R. Del Carratore, C. D. Croce, M. Simili, E. Taccini, M. Scavuzzo, and S. Sbrana, "Cell cycle and morphological alterations as indicative of apoptosis promoted by UV irradiation in $S$. cerevisiae," Mutation Research, vol. 513, no. 1-2, pp. 183-191, 2002.

[37] J. Phipps, A. Nasim, and D. R. Miller, "Recovery, repair, and mutagenesis in Schizosaccharomyces pombe," Advances in Genetics, vol. 23, pp. 1-72, 1985.

[38] V. Guacci, D. Koshland, and A. Strunnikov, "A direct link between sister chromatid cohesion and chromosome condensation revealed through the analysis of MCD1 in S. cerevisiae," Cell, vol. 91, no. 1, pp. 47-57, 1997. 

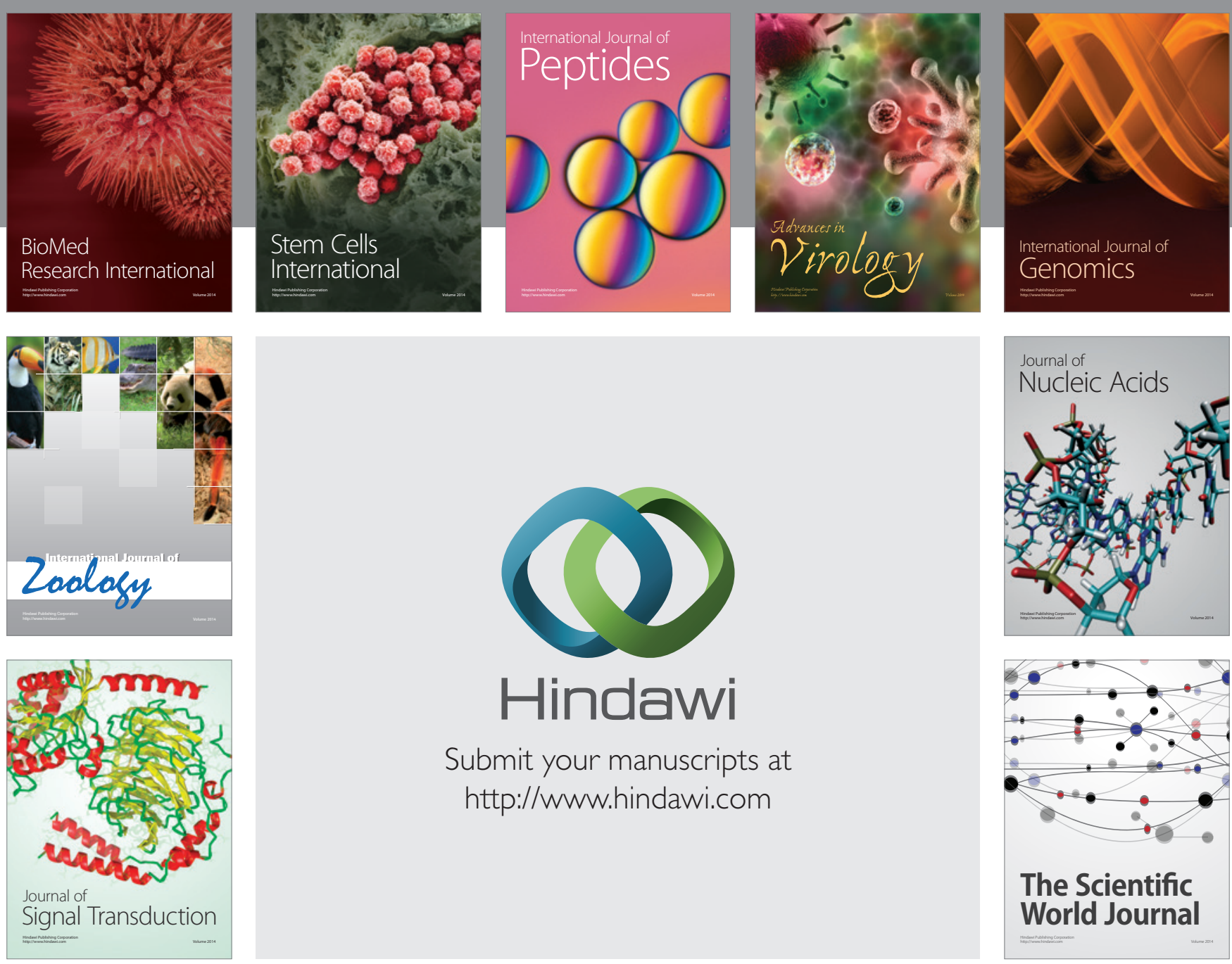

Submit your manuscripts at

http://www.hindawi.com
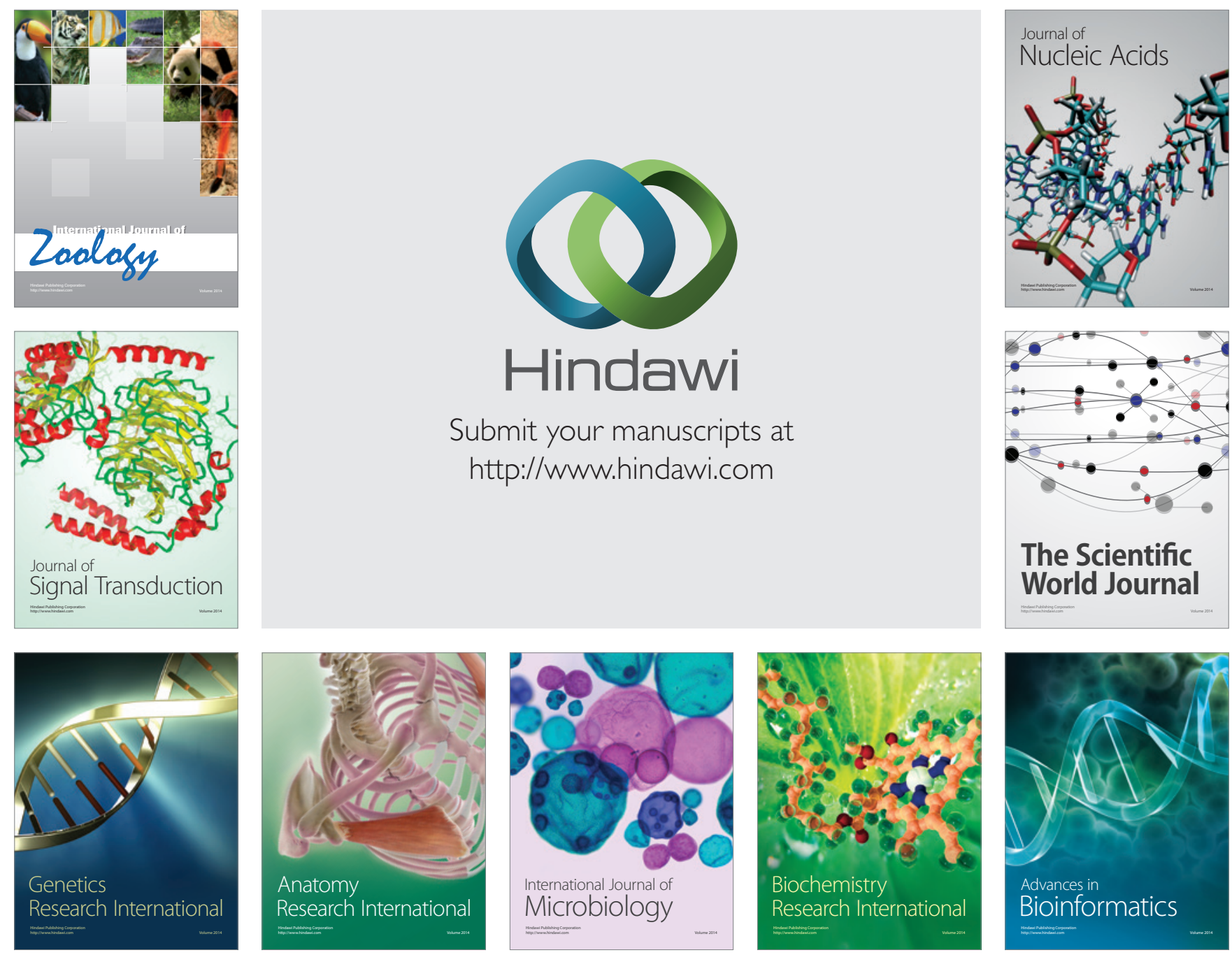

The Scientific World Journal
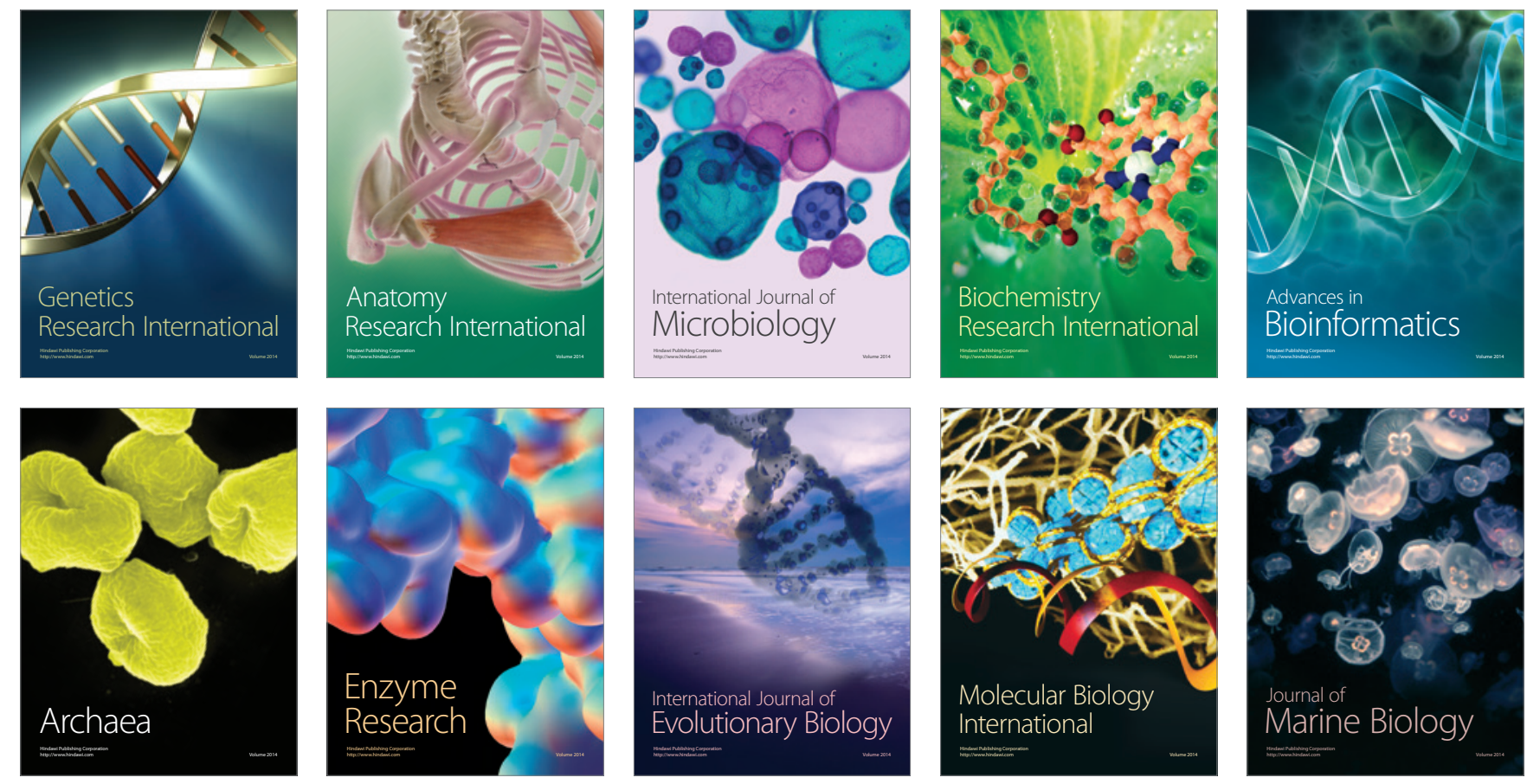